Institut für Makroökonomie und Konjunkturforschung Macroeconomic Policy Institute

\title{
Credit vs. demand constraints: the determinants of US firm-level investment over the business cycles from 1977 to 2011
}

January 10, 2013

\begin{abstract}
The paper studies empirically how relative supply and demand conditions on the capital market affected US firm-level investment over the business cycles from 1977 to 2011 . A dynamic econometric specification of capital accumulation including sales growth, Tobin's $q$, the cash flow-capital ratio and the cost of capital as covariates is fitted by a rolling window System GMM estimator using quarterly data on publicly traded US corporations in order to obtain time-varying coefficients. We find that the investment effects of the variables capturing the demand-side of the capital market, i.e. sales growth and Tobin's $q$, behave counter-cyclically, whereas this does not hold for the investment effects of supplyside variables such as cash flow or the cost of capital. Our results suggest that investment was typically driven by adverse demand rather than supply conditions on the capital market during the most severe recessions.
\end{abstract}

Keywords: investment, credit constraints, business cycles, panel estimation, System GMM

JEL Classication: D22, E22, G32

\footnotetext{
${ }^{1}$ Macroeconomic Policy Institute (IMK), Düsseldorf, Germany, Email: christian-schoder@boeckler.de
} 


\title{
Credit vs. demand constraints: the determinants of US firm-level investment over the business cycles from 1977 to $2011^{*}$
}

\author{
Christian Schoder ${ }^{\dagger}$ \\ Macroeconomic Policy Institute (IMK)
}

January 10, 2013

\begin{abstract}
The paper studies empirically how relative supply and demand conditions on the capital market affected US firm-level investment over the business cycles from 1977 to 2011. A dynamic econometric specification of capital accumulation including sales growth, Tobin's $q$, the cash flow-capital ratio and the cost of capital as covariates is fitted by a rolling window System GMM estimator using quarterly data on publicly traded US corporations in order to obtain time-varying coefficients. We find that the investment effects of the variables capturing the demand-side of the capital market, i.e. sales growth and Tobin's $q$, behave counter-cyclically, whereas this does not hold for the investment effects of supply-side variables such as cash flow or the cost of capital. Our results suggest that investment was typically driven by adverse demand rather than supply conditions on the capital market during the most severe recessions.
\end{abstract}

Keywords: investment, credit constraints, business cycles, panel estimation, System GMM

JEL Classification: D22, E22, G32

*For valuable comments and suggestions, I would like to thank Cheng Hsiao, Duncan Foley, Willi Semmler, Christian Proaño, Josh Mason, Ulrich Fritsche, Artur Tarassow, Andrew Watt and two anonymous referees as well as the participants of the 13th IWH-CIREQ Macroeconometric Workshop, "Macroeconometrics and Panel Data," Halle, Germany, December 7-8, 2012.

$\dagger$ Address: Macroeconomic Policy Institute (IMK), Hans-Böckler Str. 39, 40476 Düsseldorf, Germany. Email: christian-schoder@boeckler.de. 


\section{Introduction}

To overcome the recession following the financial crisis of 2007-09, US authorities have pursued policy measures aimed at maintaining a steady flow of credit from financial markets to businesses mainly through quantitative easing, the implementation of new lending facilities and the purchase of toxic assets by public authorities. Despite an aggressive interest rate policy as well as a stimulus package, typically Keynesian economists have expressed concerns that demand management has not been pursued to a sufficient extent as non-financial business investment declined tremendously in 2009/10.

The debate on the effectiveness of fiscal stimulus packages is primarily based on estimations of the multiplier effects of government spending. ${ }^{1}$ While this has the advantage of analyzing the overall impact of fiscal policy on GDP growth, it has a severe downside: The multiplier effect is typically not identified as government spending is endogenous to GDP growth. This issue contributes to the inconclusiveness of the studies conducted which manifests in a wide range of estimated multipliers. ${ }^{2}$ Therefore, the present paper seeks to follow a different route and analyzes how investment responded to changes in the cost of and access to finance (supply side of the capital market) and investment opportunities (demand side of the capital market) in periods of economic distress. The elasticity of investment with respect to supply and demand conditions on the capital market allows for some qualitative inference on the marginal effectiveness of fiscal and monetary policy.

The effectiveness of demand stabilizing and credit-flow sustaining policies depends on the drivers of investment. Measures that increase the willingness of the banking sector to lend may prove ineffective if firms are reluctant to expand their capital stock due to large spare capacities and a lack of investment opportunities.On the other hand, expansionary conventional monetary policy as well as fiscal policy may involve small multiplier effects on investment if firms' access to external finance is constrained.

An emphasis of policy making on the supply side of the capital market is suggested by the prevailing paradigm in investment theory which derives credit constraints on investment from information asymmetries on the capital market which drive a wedge between the costs of internal and external funds (Greenwald et al. 1984; Myers and Majluf 1984; Jensen and Meckling 1976). Problems of moral hazard arise as debtors have an incentive to engage in riskier investments once they have received the external funds. A risk premium arises which is reinforced by adverse selection, i.e. the displacement of risk averse investors by risk taking investors. Since the agency cost of investment which reflects the cost difference between external and internal funds is inversely related to a firm's net worth which behaves procyclically, the financial accelerator theory pioneered by Bernanke and Gertler (1989) predicts that, during times of economic distress, supply conditions deteriorate and the marginal costs of finance rise more than demand conditions and the marginal revenue of investment, respectively.

\footnotetext{
${ }^{1}$ See, among others, Romer and Bernstein (2009), Cogan et al. (2010) and Christiano et al. (2009) on the multiplier effects of the stimulus packages during the recent crisis.

${ }^{2}$ While Romer and Bernstein (2009) estimate a multiplier of 1.6 for the American Recovery and Reinvestment Act, Cogan et al. (2010) come up with an estimate below one.
} 
For the US corporate business sector, the present paper seeks to empirically assess the relative importance of supply and demand conditions on the capital market for explaining investment over the cycle. We motivate relative credit constraints and demand constraints, i.e. relative supply and demand conditions on the capital market, by the aid of a simple asymmetric information model of investment. On the one hand, investment demand is determined by the expected marginal profitability which, in standard investment theory, is characterized by Tobin's marginal $q$, i.e. the ratio of the market value of an additional unit of capital to its replacement cost (Tobin 1969). Moreover, empirical studies typically include accelerator terms such as current sales as a proxy for capacity utilization in the investment function (cf. Fazzari et al. 1988). On the other hand, the supply of finance is characterized by cash flow which is directly related to net worth and, therefore, inversely related to agency costs. We argue that, under some plausible assumptions, the sensitivities of investment with respect to changes of the capital supply and capital demand related variables used, are sufficiently good measures of the relative tightness of a firms' credit and demand constraints.

To study how capital market conditions prevailing in the US since 1977 changed over the business cycles, we estimate a dynamic linear investment function for a panel of US corporate businesses, including sales growth, Tobin's $q$, cash flow and the cost of capital as covariates. A rolling window regression with a width of 5 quarters has been applied in order to track the changes in the coefficients over time. Since the time dimension of the window is small while the cross-section dimension is large, we fit the dynamic model using the System GMM estimator for panel data developed by Arellano and Bond (1991), Arellano and Bover (1995) and Blundell and Bond (1998).

Based on the relative movement of the time-varying coefficients, we are able to characterize the relative supply and demand conditions on the capital market over time. The results suggest that investment tended to be driven by adverse demand rather than supply conditions during the most severe recessions. Especially, the decline of investment after the financial meltdown in 2007-08 is associated with inferior demand conditions compared to supply conditions. This view is consistent with the chronicles of US fiscal and monetary policy stance regarding the management of aggregate demand and credit flow. Our policy evaluation implies that the policy attempts to stabilize demand were insufficient in order to stabilize investment in the recent economic crisis.

Traditionally, empirical studies of credit-constrained investment analyze how cash-flow coefficients differ between sub-groups of firms grouped according to their probability of facing liquidity constraints. The study by Fazzari et al. (1988) classifies firms according to their dividend payout policy and finds that firms with low dividend payout rates which can be expected to face stronger credit constraints tend to exhibit higher cash-flow elasticities of investment. Here, we do not follow this line of research because of two reasons: First, the interest of this paper is to study how capital market conditions have changed over the cycles which is only possible by analyzing the elasticities of investment along the time dimension. Second, theoretical considerations and empirical evidence put forward, among others, in the discussion attached to Fazzari et al. (1988) as well as by Schoder (forthcoming) suggest that grouping on a priori grounds may lead to flawed results. They may be subject to a selection 
bias as they are typically highly sensitive to the choice of the sample selection criterion as well as the sample of firms considered. ${ }^{3}$

Against the time-varying approach pursued here, the criticism has been put forward that the sensitivity of investment with respect to cash flow may not reflect the tightness of the average firm's credit constraints. Abel and Eberly (2011) have shown that investment and cash flow may be correlated despite perfect capital markets, as both respond to shocks to the user cost of capital. We account for that by controlling for changes in the cost of capital in our regressions. Further, Erickson and Whited (2000) have argued that measurement errors of Tobin's $q$ may give rise to spurious correlation of investment with cash flow. Yet, erroneous measurement is argued to bias the level of the coefficients while there is no reason why it should affect their cyclical behavior. Interpreting our estimation results, we only consider the cyclical elements and not the levels of the coefficients. Finally, as shown by Kaplan and Zingales (1997), credit constraints may not be captured well by the cash-flow sensitivity of investment since the latter may not be inversely related to net worth. This result, however, relies on the assumption of a convex investment demand function which we argue is not plausible. Suggesting a concave average investment demand function is sufficient to establish a direct relationship between the cash-flow sensitivity of investment and the relative tightness of credit constraints compared to demand conditions.

Our study is related to Mason (2012) who empirically analyses the tightness of credit constraints for US business investment during the 2008/09 downturn. In particular, the cash-flow and debt sensitivities of investment are studied over time as well as for groups of firms formed along characteristics indicating the probability of facing credit constraints as suggested by economic theory. The core result is that credit constraints may have contributed to the decline of investment in the early downturn. Yet, after the collapse of Lehman, which is considered to be the beginning of the worst credit market conditions, credit constraints seem to have played a minor role. The present paper extends this study by analyzing investment over the business cycles since 1977, providing the theoretical foundation of the econometric model and applying a more advanced econometric methodology which allows for consistently estimating dynamic investment functions and accounts for the endogeneity of the covariates.

The remainder of the paper proceeds as follows. Section 2 illustrates the underlying theoretical investment model as well as the constellations of the investment demand and finance supply curves. It also discusses the econometric model used for the empirical analysis. Section 3 outlines the System GMM estimator for panel data which is the econometric methodology applied to estimate the dynamic investment specification in a recursive manner. In section 4 , the data set used and variables computed are discussed. Section 5 presents the estimation results. Section 6 interprets the cyclical behavior of credit and demand constraints in the context of the historical record of monetary and fiscal policy aimed at the management of aggregate demand and credit flows. Section 7 concludes the paper.

\footnotetext{
${ }^{3}$ As argued in the discussion attached to Fazzari et al. (1988), an endogeneity issue arises as firms with good investment prospects which may be partly reflected by a large cash flow are likely to choose a low dividend payout rate. Schoder (forthcoming) finds empirical evidence that the differences between the cashflow coefficients across groups formed based on a priori assumptions about liquidity constraints such as size and dividend payout policy are not robust.
} 


\section{An econometric model of investment}

\subsection{A simple model of investment}

Consider the following investment model with asymmetric information between lenders and borrowers in the vain of Gertler and Hubbard (1988) and Bernanke and Gertler (1989). In period zero, a risk neutral representative firm in a competitive market produces output from capital, $K$. Output becomes available for consumption in period one. Two states may arise: In state 1 (which is the "bad" state and occurs with probability $\pi_{1}$ ), $K$ units of capital are transformed into $\alpha f(K)$ units of output with $0<\alpha<1$; in state two (which is the "good" state and occurs with probability $\left.\pi_{2}\right), f(K)$ units of output are produced.

The production function, $f(K)$, is assumed to be at least once differentiable. It is assumed to characterize the following technology. Let there be an additional factor of production such as land which is not explicitly modeled. At low $K$ 's, $f^{\prime}(K)$ is constant due to the abundant availability of land. At higher $K$ 's, decreasing returns set in. Not only does $f^{\prime}(K)$ decrease, $f^{\prime \prime}(K)$ also decreases as it is assumed that the elasticity of substitution between capital and land decreases with increasing $K$. Such a production technology, $f(K)$, exhibits a decreasing and concave investment demand schedule.

To finance the desired investment, firms may borrow from competitive lenders an amount $K-W$ if their net worth, $W$, is insufficient. The interest rate on external funds is $r$. An information asymmetry arises from the assumption that only the firm can observe the realized state for free but not the lenders. Yet, the lenders may audit the firm's announcement which implies a cost of $\gamma K$ units of output. The cost of audit is assumed to rise with the capital investment, as, in practice, the state verification is more difficult with large investments than with small ones. Since for the case of only two possible states Bernanke and Gertler (1989) showed that lenders only audit in the bad state, we assume this a priori. The probability of an audit is $p$. The cost of borrowing in the bad state with auditing, in the bad state without auditing and in the good state are $P^{a}+\gamma K+r K, P_{1}+r K$ and $P_{2}+r K$, respectively, with $P^{a}, P_{1}, P_{2}$ being payments additional to interest rate.

The total expected revenues and the total expected costs are

$$
R=\pi_{1} \alpha f(K)+\pi_{2} f(K)
$$

and

$$
C=\pi_{1} p\left(P^{a}+\gamma K+r(K-W)\right)+\pi_{1}(1-p)\left(P_{1}+r(K-W)\right)+\pi_{2}\left(P_{2}+r(K-W)\right),
$$

respectively.

The problem is to find the optimal contract characterized by $p, P^{a}, P_{1}$ and $P_{2}$ and the optimal investment, $K$. It is solved by maximizing expected profits, i.e.

$$
\max R-C
$$

subject to the following constraints: First, the expected payoff for the lenders has to be larger than the opportunity cost of lending. In fact, due to the assumption of competitive 
capital markets, this constraint is always binding, i.e.

$$
\pi_{1} p\left(P^{a}+r(K-W)\right)+\pi_{1}(1-p)\left(P_{1}+r(K-W)\right)+\pi_{2}\left(P_{2}+r(K-W)\right)=r(K-W) .
$$

Second, in order to prevent the firm from lying about the true state, the expected profit must not be lower than the expected profit given the firm announces the bad state regardless of the true state. Hence,

$$
\begin{aligned}
R-C & \geq R-\left[\pi_{1} p\left(P^{a}+\gamma K+r(K-W)\right)+\pi_{1}(1-p)\left(P_{1}+r(K-W)\right)\right. \\
& \left.+\pi_{2} p\left(P^{b}+\gamma K+r(K-W)\right)+\pi_{2}(1-p)\left(P_{1}+r(K-W)\right)\right],
\end{aligned}
$$

where it can be shown that $P^{b}=f(K)-\gamma K-r(K-W)$. The amount a firm can credible promise to be liable for in the case of insolvency is limited by its net worth. Hence,

$$
P_{1} \leq \alpha f(K)-r(K-W)
$$

and

$$
P^{a} \leq \alpha f(K)-\gamma K-r(K-W) .
$$

Obviously, it must hold for the audition probability that

$$
0 \leq p \leq 1
$$

Two scenarios may arise. First, the firm's net worth is large enough to pay the lenders their required return even in the bad case, i.e. $\alpha f(K) \geq r(K-W)$, or auditions are costless, i.e $\gamma=0$. In either case, no agency problem arise. Equations (5) to (7) do not bind and the optimal audition probability, $p$, is zero. Substituting (1), (2) and (4) into (3), the first oder condition with respect to $K$ implies that the optimal investment is where marginal revenue equals marginal cost. The investment demand schedule is $\left(\pi_{1} \alpha+\pi_{2}\right) f^{\prime}(K)$ and the supply of finance schedule is $r$.

As soon as the desired capital stock exceeds the net worth, agency costs of external finance rising with investment at a given net worth arise. Then, equations (5) to (7) start binding which yields a system of four equations in five unknowns. Adding the term $\pi p \gamma K$ to either side of (4) and substituting the resulting left-hand-side as well as (7) and (8) into (5), one can solve for the $p$ conditional on $K$, i.e.

$$
p(K)=\frac{r(K-W)-\alpha f(K)}{\pi_{2}(1-\alpha) f(K)-\pi_{1} \gamma K}
$$

Using (1), (2), (6), (7) and (9), (3) can be maximized with respect to $K$. The investment demand schedule is the same as in the case without agency costs. The marginal cost schedule, i.e. supply of funds schedule, can be shown to be increasing and strictly convex on the relevant domain. 


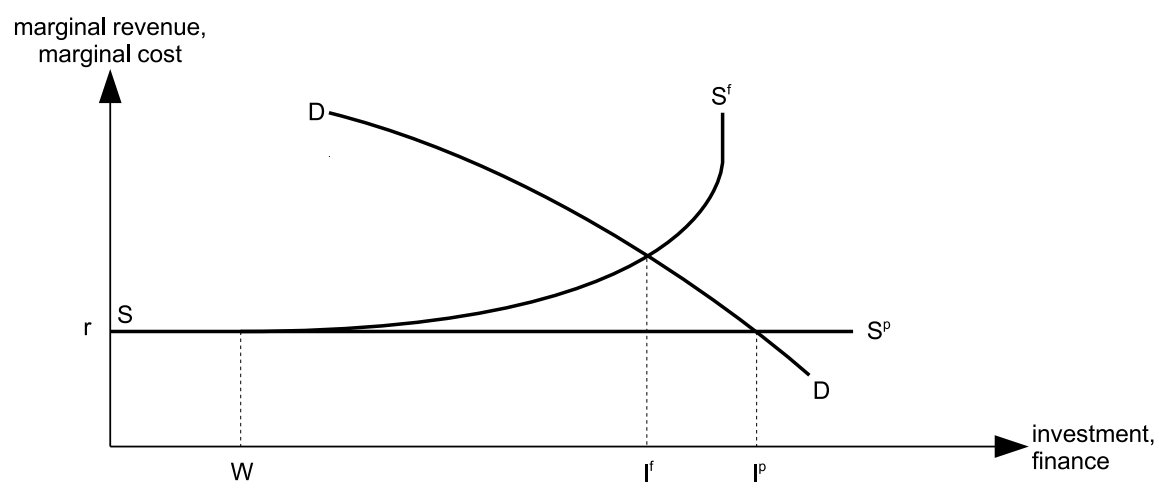

Figure 1: Capital market

\subsection{Supply and demand conditions over the cycle}

To motivate our econometric specification we briefly conduct a graphical analysis of the links between capital investment, agency cost of external finance and investment opportunities based on the investment model outlined above. Figure 1 illustrates a simple capital market characterizing the model, i.e. an investment demand curve and two variants of the supply of funds curve of an average firm.

The demand curve DD reflects an inverse relationship between the marginal revenue of investment and the desired capital expansion. The curve $\mathrm{SS}^{p}$ relates the supply of funds to its marginal cost on a perfect capital market. Since the firm is small, it can borrow whatever desired at the given risk-adjusted real interest rate. Given its demand curve, the firm's optimal investment is $I^{p}$. $\mathrm{SS}^{f}$ describes the supply curve in an imperfect capital market with information asymmetries between lenders and borrowers. It implies that firms prefer internal finance over external finance. As long as the desired investment is lower than the firm's internal funds, $W$, the real interest rate applies as an opportunity cost. Beyond $W$, the firm has to acquire external funds. Due to asymmetric information additional costs of external funds arise which are increasing in the amount borrowed. The supply curve on an imperfect capital market is increasing and convex as shown in the model above. The equilibrium in this market is $I^{f}<I^{p}$.

A rise (fall) in investment opportunities, i.e. the expected profitability of an additional unit of capital, shifts the demand curve to upwards (downwards). A rise (fall) in the internal funds shifts the supply curve to the right (left).

The investment-internal funds sensitivity, $\partial I^{f} / \partial W$, can be taken as a measure for creditmarket tightness as long as it is monotonically decreasing in the level of $W$. Otherwise, a firm with little internal funds facing large borrowing costs may appear facing less tight credit markets than a firm with large internal funds facing low borrowing costs (cf. Kaplan and Zingales 1997; Fazzari et al. 2000). However, a non-convex demand curve combined with a convex supply curve which are implied by the investment model outlined above are sufficient to ensure that the investment-internal funds sensitivity is monotonically decreasing in $W$.

This graphical framework can be used to study the cyclical behavior of investment. In 


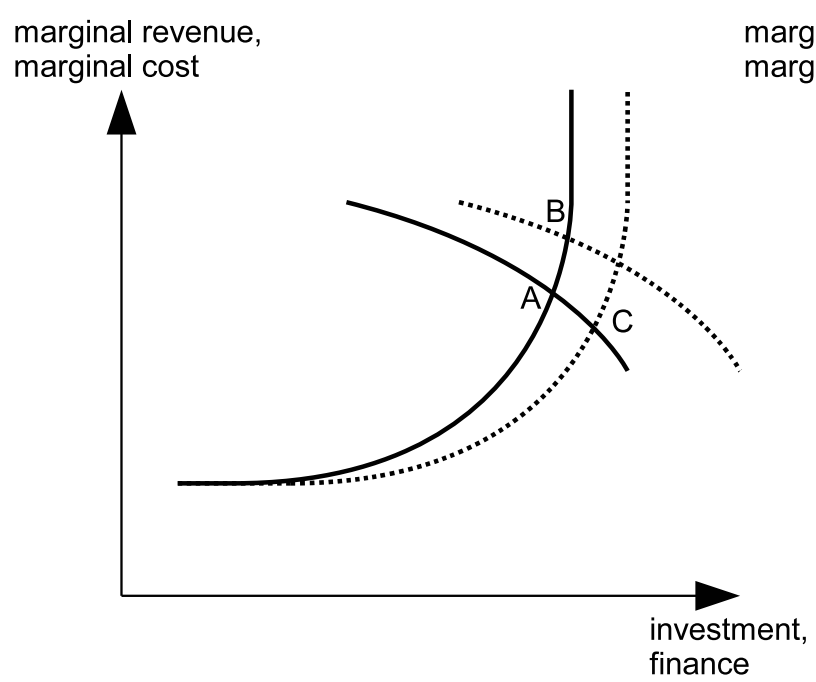

(a) marginal revenue, arginal cost

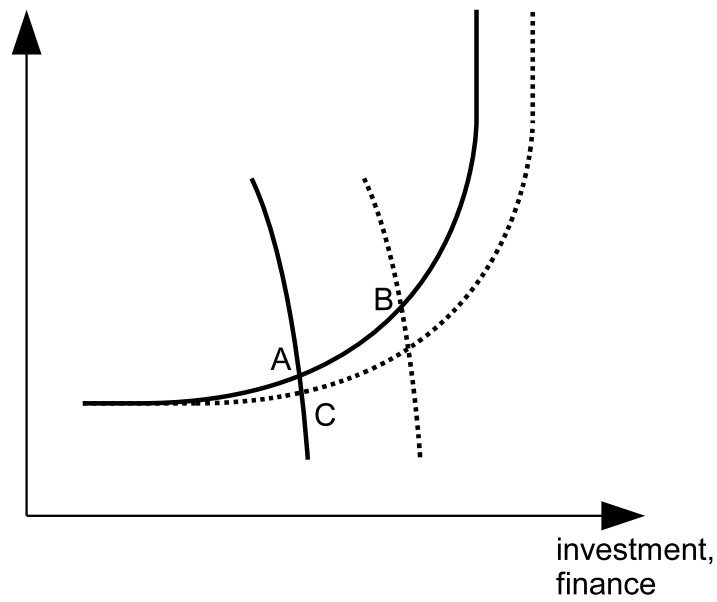

(b)

Figure 2: Different stylized investment regimes: (a) credit-constrained and (b) demandconstrained

a boom, expectations improve and investment opportunities rise increasing the expected marginal revenue at any level of investment. In the upswing, firms tend to rise their profit margins expanding their internal funds which shifts the supply curve to the left. Moreover, tightening of monetary policy causes the market interest rates to go up shifting the supply curve upwards. In the downswing, usually the opposite is observed.

The slopes of the supply and demand curves characterize conditions on the capital market. Figure 2 illustrates different stylized demand and supply constellations. Panel (a) represents a capital market with rather tight credit constraints. The demand schedule cuts the supply curve at $A$ where the latter is fairly steep. This constellation has the following implications: First, a rise in investment opportunities which may be triggered by expansionary fiscal policy is rather ineffective in raising investment moving the new equilibrium to $B$. Second, measures aimed at expanding the firms' cash flow, for instance, through tax cuts move the supply curve to the left and are highly effective in fostering investment. The same holds for measures seeking to lower the agency cost of external finance through conventional and unconventional monetary policy which stretches and reduces the slope of the increasing segment of the supply curve. Together these measures imply a new equilibrium at $C$.

Panel (b) illustrates a demand-constrained capital market with elastic supply but inelastic demand, i.e. with banks eager to lend but firms not willing to borrow. The relevant segment of the demand curve is steep, i.e. firms do not increase investment to a great extent even if the cost of capital decreases a lot. The supply curve is cut in a rather flat segment in point $A$. In this case, an increase in the investment opportunities shifting the demand curve upwards has a large effect on investment $(B)$. Lowering the agency cost of external funds $(C)$ has low effects on investment. 
The financial accelerator theory predicts the economy to move towards the credit-constrained rather than the demand-constrained constellation during downturns. In the following we study this hypothesis, in particular the behavior of relative supply and demand conditions over the cycle, empirically.

\subsection{The econometric specification}

For the econometric analysis, we approximate the supply and demand curves around the equilibrium by linear functions and normalize investment by the capital stock. Investment supply, $g^{s}$, is

$$
g^{s}=\alpha_{1} a_{t}+\beta_{1} M C_{t}+\varepsilon_{1, t}
$$

and investment demand, $g^{d}$, is

$$
g^{d}=\alpha_{2} b_{t}-\beta_{2} M R_{t}+\varepsilon_{2, t}
$$

where $M C_{t}$ and $M R_{t}$ are marginal costs and marginal revenues, respectively. $a_{t}$ and $b_{t}$ denote the variables affecting investment supply and demand which are independent of marginal costs and revenues, respectively. Note that the lower the slope parameter $\beta_{1}$, the worse conditions are on the supply side of the capital market. For instance, a small $\beta_{1}$ would imply agency costs to increase strongly as the supply of external funds is expanded. The slope parameter $\beta_{2}$ reflects the elasticity of the demand schedule.

The variable $a_{t}$ represents changes in net worth as well as changes in the interest rate which shift the supply curve. In the literature, the firm's cash flow is typically used as a proxy for changes in the net worth. ${ }^{4}$ Hence, we specify $a_{t}$ as

$$
a_{t}=r_{t}+\omega_{1} j_{t}
$$

where $r_{t}$ and $j_{t}$ are the cash flow-capital ratio and the interest rate, respectively.

The variable $b_{t}$ represents investment opportunities of the firm which we approximate by two variables: First, note that introducing convex adjustment costs to the investment model above, one can show that the shadow price of a marginal unit of capital, Tobin's marginal $q$, fully describes expected profitability (Tobin 1969). Yet, as this variable is not observable, the empirical literature typically approximates it with Tobin's average $q$, i.e. the ratio of capital stock's market value to its replacement cost, which equals marginal $q$ if constant returns to scale and perfect competition are assumed (Hayashi 1982). ${ }^{5}$

Second, as the data allows only for a rough approximation of the investment opportunities by $q$, its empirical performance has proven to be notoriously poor. To prevent shifts in the

\footnotetext{
${ }^{4}$ The cash flow, however, can be expected to be correlated with investment opportunities. Yet, both Tobin's $q$ and sales growth control for expected profitability as introduced below.

${ }^{5}$ An exception is Gugler et al. (2004) who estimated Tobin's marginal $q$. We followed their approach, but the estimated variable proved to be mostly insignificant in the succeeding regressions. Hence, we report the results with Tobin's average $q$ only.
} 
net worth from capturing the part of the variance in the residuals caused by the investment opportunities not captured by $q$-a point raised by Abel and Eberly (2011) and Erickson and Whited (2000)-it is common in the empirical investment literature to include a sales related measure as another proxy for expected profitability. ${ }^{6}$

Hence, we specify $b_{t}$ as

$$
b_{t}=s_{t}+\omega_{2} q_{t}
$$

where $s_{t}$ is the growth rate of sales and $q_{t}$ is Tobin's average $q$.

Using (12), (13) as well as the equilibrium condition $M C_{t}=M R_{t}$, solving (10) and (11) for $M C_{t}$ and substituting the solution back into (10), yields the reduced form investment function,

$$
g_{t}=\phi_{s} s_{t}+\phi_{q} q_{t}+\phi_{r} r_{t}+\phi_{j} j_{t}+\varepsilon_{t}
$$

with

$$
\begin{aligned}
\phi_{s} & =\alpha_{2}\left(\frac{\beta_{1}}{\beta_{1}+\beta_{2}}\right), \\
\phi_{q} & =\alpha_{2} \omega_{2}\left(\frac{\beta_{1}}{\beta_{1}+\beta_{2}}\right), \\
\phi_{r} & =\alpha_{1}\left(\frac{\beta_{2}}{\beta_{1}+\beta_{2}}\right), \\
\phi_{j} & =-\alpha_{1} \omega_{1}\left(\frac{\beta_{2}}{\beta_{1}+\beta_{2}}\right), \\
\varepsilon_{t} & =\frac{\beta_{2}}{\beta_{1}+\beta_{2}} \varepsilon_{1, t}+\varepsilon_{2, t} .
\end{aligned}
$$

We assume the accumulation rate of firm $i$ to be determined by the following data generating process:

$$
\begin{aligned}
g_{i, t} & =\sum_{k=1}^{L} \beta_{g, k} g_{i, t-k}+\sum_{k=0}^{L} \beta_{s, k} s_{i, t-k}+\sum_{k=0}^{L} \beta_{q, k} q_{i, t-k}+\sum_{k=0}^{L} \beta_{r, k} r_{i, t-k} \\
& +\sum_{k=0}^{L} \beta_{j, k} j_{i, t-k}+\sum_{s=0}^{4} \beta_{d, s} d_{s}+\mu_{i}+\varepsilon_{i, t}
\end{aligned}
$$

where $g_{i, t}, s_{i, t}, q_{i, t}, r_{i, t}$, and $j_{i, t}$ are the rate of capital accumulation, the growth rate of sales, Tobin's average $q$, the cash flow-capital ratio and the cost of capital for firm $i$ in time $t . d_{s}$

\footnotetext{
${ }^{6}$ Early accelerator theories of investment derive a positive relationship between capital expansion and changes in sales from a production function with decreasing returns to scale with fixed factor proportions (cf. Eisner 1960).Abel and Blanchard (1986) set up a general accelerator model which features a positive relationship between investment and sales in levels. Influential recent empirical studies of firm-level investment expenses using sales either in levels or in differences as a covariate are, among others, Fazzari et al. (1988) and Chirinko et al. (1999).
} 
with $s=\{1,2,3,4\}$ are seasonal dummies. $\mu_{i}$ are unobserved fixed firm effects and $\varepsilon_{i, t}$ are idiosyncratic random disturbances. ${ }^{7}$ We define

$$
\phi_{x} \equiv \frac{\sum_{k=0}^{L} \beta_{x, k}}{1-\sum_{k=1}^{L} \beta_{g, k}}
$$

as the average long-run response of $g$ to a one-unit change in variable $x$.

Lags of the covariates have been included in (20) as investment expenses do not adjust instantaneously to changes in investment opportunities, cash flow and the cost of capital. This is because expectations of future sales may depend on past sales, costs of adjustment may slow down the adjustment process, and delivery lags may delay investment expenditures (cf. Abel and Blanchard 1986). Pre-analysis of the firm-level data on investment strongly suggests that the accumulation rate exhibits strong autocorrelation. Therefore, we also include lags of the dependent variable as regressors.

\subsection{Identification issues}

The parameters of the supply and demand equations and, therefore, the slope coefficients $\beta_{1}$ and $\beta_{2}$ are not identified in the reduced form investment function. Yet, these parameters are of interest since they indicate the credit market conditions and the demand side conditions, respectively.

However, for the purpose of the present paper, which is to analyze the relative importance of supply and demand condition on the capital market, a full identification of the parameters is not required as long as the parameters determining the intercepts of the curves are acyclical. Assuming $\alpha_{1}, \alpha_{2}$ as well as $\omega_{1}$ and $\omega_{2}$ to be a-cyclical and only the slope parameters $\beta_{1}$ and $\beta_{2}$ to vary over the cycle, counter-cyclical $\phi_{s}$ and $\phi_{q}$ as well as a pro-cyclical $\phi_{s}$ imply the ratio between $\beta_{1}$ and $\beta_{2}$ to move pro-cyclically as can be readily seen by (15). Under the assumption of a-cyclical $\alpha_{1}, \alpha_{2}, \omega_{1}$ and $\omega_{2}$, the coefficients of the reduced-form investment function provide the required information on the supply and demand conditions of the capital market. The larger (smaller) $\phi_{s}$ and $\phi_{q}$ compared to $\phi_{r}$, the worse (better) conditions are on the demand side of the capital market compared to conditions on the supply side and, therefore, the closer (more distant) firms will be to (from) demand constraints rather than credit constraints.

Notice that the coefficient of the reduced-form investment function interpreted in the context of the investment model outlined above does not reflect the absolute importance of supply and demand conditions on the capital market. For instance, a large $\phi_{s}$ and a low $\phi_{r}$ may be consistent with both a large and low $\beta_{1}$ and $\beta_{2}$. The coefficients only capture the slope of one curve relative to the slop of the other. Yet, for assessing the relative importance of supply and demand constraints, this is sufficient as long as the parameters determining the intercepts are a-cyclical.

\footnotetext{
${ }^{7}$ Note that the heteroskedasticity in the disturbance term evident from (19) is taken care of by the two-step GMM estimator used.
} 
The assumption of $\alpha_{1}, \alpha_{2}, \omega_{1}$ and $\omega_{2}$ to move a-cyclically is not restrictive for the following reason: These parameters can be traced back to deep parameters of the representative agent within the financial accelerator framework and can, therefore, be taken as a-cyclical. Yet, the slope parameter of the investment supply curve is predicted to be cyclical as it depends on the agency costs which in turn depend on the net worth of the firm. Note that the intercepts may still change cyclically. Yet, this is driven by movements in $u_{t}, q_{t}$ and $r_{t}$ and not their parameters.

\section{Estimation strategy}

The General Method of Moments (GMM) allows us to obtain consistent parameter estimates even though endogenous regressors remain in the specification. ${ }^{8}$ The idea of the GMM estimator is to exploit moment conditions which are assumed to hold, in order to come up with a consistent estimate of the parameter vector. Parameter estimates are obtained by choosing the vector of coefficients such that a weighted quadratic form of the empirical moment conditions is minimized. This sum is usually larger than zero as there are, in general, more moment conditions to exploit than parameters to estimate. The choice of the weighting matrix is crucial for the efficiency of the estimator, yet irrelevant for its consistency. Moments with lower variance and covariance should be given more weight. Whereas the onestep GMM estimator simply chooses an optimal weighting matrix under the assumption of spheric disturbances, the two-step GMM estimator employs the residuals of an auxiliary regression to obtain a consistent estimate of the weighting matrix which implies the GMM estimator to be efficient. ${ }^{9}$

Arellano and Bond (1991), Arellano and Bover (1995) and Blundell and Bond (1998) applied the GMM framework to dynamic panels and developed estimators which are able to cope with the correlation between the unobserved fixed group effects and the lags of the dependent variables as well as the endogeneity of other regressors without requiring the researcher to find suitable instruments outside the sample at hand.

Difference GMM and System GMM are two methods to deal with the endogeneity of the lagged dependent variable and of other regressors. Difference GMM developed by Arellano and Bond (1991) applies a first-difference transform to the data in order to eliminate the fixed effects. The lags of the dependent variable on the right-hand side may still be endogenous after taking first differences. Yet, in contrast to a Within Group transform, lags longer than

\footnotetext{
${ }^{8}$ Since the lags of the dependent variable are positively correlated with the fixed firm effects included in the disturbance terms and none of the contemporaneous values of the independent variables can be plausibly assumed to be exogenous, i.e. they are most likely correlated with the idiosyncratic shocks, pooled estimation of (20) by OLS is not an option. Also estimating (20) by OLS after removing the fixed firm effects by applying a within transform to the data by which the group-mean is subtracted from each variable (fixed effects estimator) and dropping the contemporaneous values of the independent variables will yield biased estimates. Although this procedure gets rid of the most pronounced biases in the numerator of the long-run coefficients in (21), the estimates for the lagged dependent variables are now downward biased, i.e the denominator in (21) is upward biased and the long-run coefficient overall is downward biased.

${ }^{9}$ Appendix B formally derives of the one and two-step estimators.
} 
the lags included in the specification remain orthogonal to the disturbances and, therefore, available as instruments. To overcome the trade-off between lag length and sample size which is a common problem of the conventional 2SLS estimator and arises from the elimination of observations for which lagged values are missing, so-called "GMM-style" instruments in levels are constructed which imply a different set of instruments for each period and replace missing values by zeros.

Blundell and Bond (1998) build on Arellano and Bover (1995) seeking to further increase the efficiency of the GMM estimator under additional assumptions. They develop System GMM which exploits the moment conditions of Difference GMM for transformed data as well as an additional set of moment conditions for untransformed data derived from the assumption that the first differences of any variable used as an instrument are uncorrelated with the fixed group effects. In this case, the endogeneity of the untransformed lagged dependent variable arising from its correlation with the fixed effects can be resolved by instrumenting it with transformed, i.e. first-differenced, lags. ${ }^{10}$

\section{Data}

We use quarterly firm-level data obtained from S\&P's Compustat North America Fundamentals Quarterly database. It includes data on the balance sheets and income statements of publicly traded corporations. We excluded the finance, insurance and real estate sectors (SIC codes 6011 to 6799 ) as their investment dynamics can be expected to deviate substantially from the rest of the private business sector.

For the econometric analysis, the following variables have been computed: The accumulation rate, $g$, is the quarterly growth rate of the real net stock of capital in property, plant and equipment. The rate of sales growth, $s$, is the growth rate of real net sales. The cash flow-capital ratio, $r$, is defined as real after-tax income normalized by the beginning-of-period real net capital stock. Tobin's average $q$ is approximated by the sum of the market value of equity and the book value of total debt, divided by the book value of total assets. To compute the cost of capital, $j$, we follow Fazzari and Athey (1987) by using the capital asset pricing model (CAPM) to estimate a firm-specific measure. ${ }^{11}$

A few remarks on the construction of the variables are in order. First, the change in the net capital stock is used as a proxy for investment as the coverage of capital expenses in the firms' cash flow account is insufficient for our purposes. Moreover, the quality of the

\footnotetext{
${ }^{10}$ Difference GMM and System GMM are formally derived in Appendix C.

${ }^{11}$ The CAPM postulates that the rate of return on assets required by asset holders equals the risk-free rate plus the market price of risk weighted by the so-called beta-coefficient, i.e. the extent to which a return of an asset varies with the market. We estimate the required asset return using Moody's Aaa bond rate as the risk free rate, the difference between the Aaa and Baa bond rate as the market price of risk and, as the asset beta, the equity beta reported in the Compustat database, averaged over time for each firm and adjusted by the debt-asset ratio. The adjustment is required as we are interested in the asset beta which is the weighted sum of the debt beta and the (reported) equity beta with the debt-asset ratio and the equity-asset ratio being the respective weights. We follow Fazzari and Athey (1987) by assuming that the debt beta is zero. A description of all variables and the data sources is provided in Appendix A.
} 
quarterly year-to-date data on capital expenses as a quarterly measure is questionable as many firms appear to report the yearly capital expenses in the fourth quarter of the year. The correlation between the growth rate of the capital stock and the capital expenses-capital stock ratio is around $75 \%$.

Second, in order to be consistent with our dependent variable, we relate the cash flow net of depreciation to the net capital stock. Surprisingly, related studies such as Gugler et al. (2004), Fazzari et al. (1988) as well as Gilchrist and Zakrajsek (2007) relate the cash flow including deprecation to the net capital stock. In the course of time, this, ceteris paribus, necessarily leads to a rising cash flow-capital ratio and may thus create distortions.

Third, we follow Chung and Pruitt (1994) and construct an approximation of Tobin's average $q$ which has been found to explain at least $96.6 \%$ of $q$ constructed according to Lindenberg and Ross' (1981) procedure. This is in line with the literature such as Gilchrist and Zakrajsek (2007) and Gugler et al. (2004).

After applying a standard screening procedure to the data with the aim of removing outliers and condensing the data, which is discussed in greater detail in Appendix A, the final data set shrunk to 311,892 observations and 10,426 firms covering the period from 1975:1 to 2010:4. Note that observations with a non-positive cash flow have been removed. As documented by Schoder (forthcoming), the marginal effect of cash flow on investment is lower with negative realizations than with positive ones as firms usually do not reduce their capital stock in the case of negative profits to the same extent as they raise their capital stock in the case of positive profits. Using unfiltered data, this asymmetry in the cashflow elasticity of investment implies a strong cyclical behavior of the cash flow-capital ratio coefficient as profits decrease in the downturn implying a lower estimated coefficient. Since the main interest of the present paper is to study the cyclical behavior credit constraints approximated by the cash-flow elasticity of investment, we only consider observations with positive cash flows and exclude the possibility that a cyclical behavior of the cash flow-capital ratio coefficient is driven by an asymmetry in the cash-flow elasticity of investment as found by Schoder (forthcoming).

\section{$5 \quad$ Empirical analysis}

Figure 3 depicts the aggregate rate of capital accumulation for the US non-farm non-financial corporate business sector since the 1970s. ${ }^{12}$ A heat map indicates the business cycle. The more intense the color, the slower the economic expansion. As a business cycle measure we use an index for business confidence also known as the Purchasing Managers Index computed by the Institute of Supply Management. It is a composite index using information on production levels, new orders, supplier deliveries, inventories, employment levels of US man-

\footnotetext{
${ }^{12}$ The capital accumulation rate is gross fixed investment in non-residential equipment, software and structures divided by fixed assets in non-residential equipment and software and non-residential structures of the non-farm non-financial corporate business sector. The data has been taken from the Flow of Funds Account of the US published by the Fed.
} 


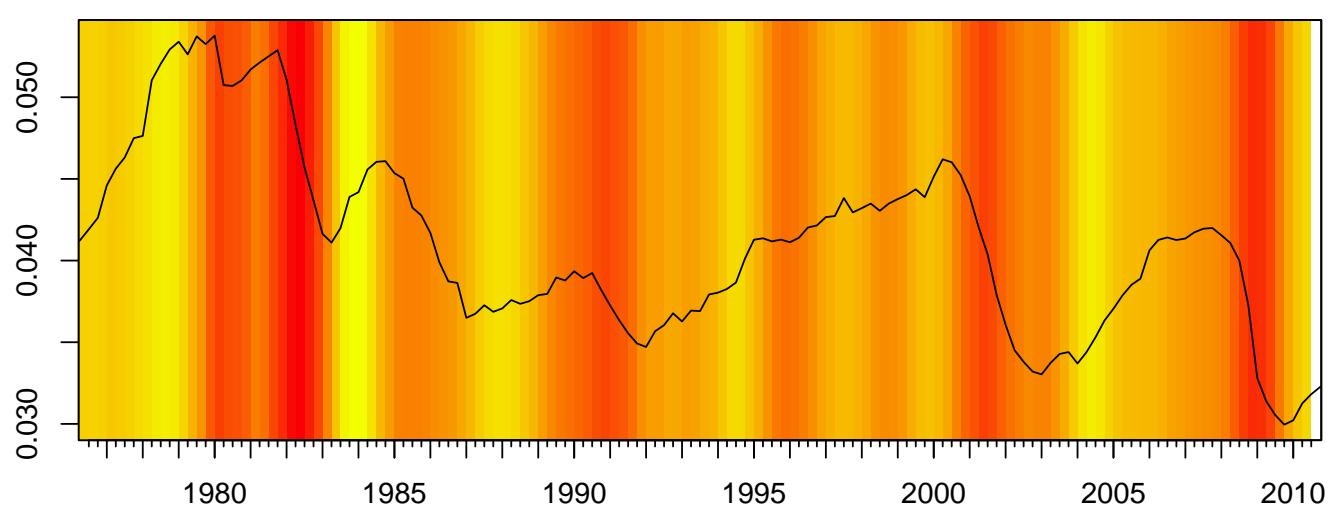

Figure 3: Aggregate capital accumulation rate for the US non-farm non-financial business sector (Source: Fed)

ufacturing firms. ${ }^{13}$ Note that the business cycle indicator has been smoothened to facilitate readability.

Unsurprisingly, the rate of capital accumulation exhibits a strong pro-cyclical pattern. The recessions in the early 1980s, the mid-1980s, the early 2000s and the recent crisis in the late 2000s featured the largest declines in the accumulation rate. The last recession saw a slow-down of the speed of capital accumulation to the lowest rate measured in the entire period considered. In the beginning of 2011 the accumulation rate appears to be still below both average and trend.

\subsection{Estimation results}

For estimating (20), we choose a lag length of $L=4$ as the standard specification. ${ }^{14}$ To estimate this specification consistently we use the two-step System GMM estimator. Since the idiosyncratic shocks in (20) are likely to be correlated with the contemporaneous values of $s, q, r$ and $j$, we take these variables as endogenous.

Since we are interested in the cyclical behavior of the long-run coefficients, we apply a rolling window procedure in order to obtain time-varying coefficients. We recursively estimate the investment function for samples spanning over five consecutive quarters, moving from the beginning to the end of the period considered. For each of the samples, the respec-

\footnotetext{
${ }^{13}$ Alternatively, we experimented with the growth rate of GDP as a business cycle indicator which yielded a similar heat map.

${ }^{14}$ This decision is based on the analysis of dynamic correlograms which indicate a decline of the correlation between accumulation and the lags of the explanatory variables when $L \geq 5$. However, we report the results obtained with $L=3$ and $L=5$ as robustness checks in Appendix D. The main results are robust to the lag length chosen.
} 
tive long-run coefficients are then calculated according to (21). Since we are not primarily interested in quarter-to-quarter fluctuations which blur the overall picture, the series of long-run coefficients have been smoothened by applying 5-quarter two-sided moving average filters.

To analyze the cyclical behavior of the estimated long-run coefficients, the line plots are contrasted by the heat map indicating the business cycle. Figure 4 depicts the results for the two-step System GMM estimation of (20) with $L=4$ for publicly traded North American firms. The first four panels of the figure show the smoothed time-varying long-run coefficients obtained by rolling regressions applying a window of 5 quarters as well as the $95 \%$-confidence intervals. The last panel reports the Arellano-Bond test for zero second-order autocorrelation in first-differenced errors with the null hypothesis of no autocorrelation. ${ }^{15}$

The estimates for the sales growth's long-run effect on investment oscillate around 0.1 . The confidence interval indicates that the estimates are mostly significant at the $5 \%$ level. Apart from the early 1980s which featured high coefficients for Tobin's $q$, its long-run effects fluctuates around 0.01 and is mostly significant at the 5\% level. The cash-flow's long-run coefficient exhibits a decreasing trend (from around 0.15 to around 0.05 ) which is consistent with the view that financial market integration and innovation alleviated the firms' access to credit over the last decades. The coefficient is also mostly significant. The coefficient for the cost of capital fluctuates without significant trend around zero and is usual insignificant at the $5 \%$ level. $^{16}$

More interesting than the trends are the cyclical components of the estimated long-run coefficients as they, analyzed jointly, allow us to empirically assess capital market conditions outlined in the theoretical section. Before analyzing each cycle individually, note the following: First, the effect of sales growth on investment exhibits in general a strong cyclical behavior. In downturns the coefficient tends to go up significantly. Further, the coefficient tends to be the higher the lower the business confidence. Notice the exception of the 2001 recession during which investment was not very overly sensitive to changes in sales growth. Second, the long-run coefficient for Tobin's $q$ exhibits a similar cyclical behavior. The coefficient tends to go up during severe downturns such as the double-dip recession in the early 1980's and, to a lesser extent, during the S\&L crisis in the early 1990s, the burst of the dot-com bubble in 2001 and the recent financial meltdown in 2009. Overall, demand expectations tend to be an important determinant of investment during times of economic distress. Third, the cash-flow coefficient does not exhibit a straightforward cyclical pattern. According to our results, strong cash-flow effects were present only in the recession following the interest rate shock in the late 1970s, weaker ones during the mild downturns in business confidence in 1995 and 1998. In neither the 2001 nor the 2009 recessions, investment was much driven by cash flow. Quite the contrary, the cash flow coefficient dropped considerably. Fourth, the fluctuations of the cost of capital's coefficient are difficult to interpret. Moreover,

\footnotetext{
${ }^{15}$ The Sargan test of over-identifying restrictions (with the null hypothesis that the over-identifying restrictions are valid) cannot be applied to the two-step estimator.

${ }^{16}$ Note that the trends of the coefficients have to be interpreted with caution as the number of publicly traded firms increased over time. However, our main results are based on the cyclical behavior of the estimated coefficients which can be expected to be rather insensitive to the changing size of the sample.
} 

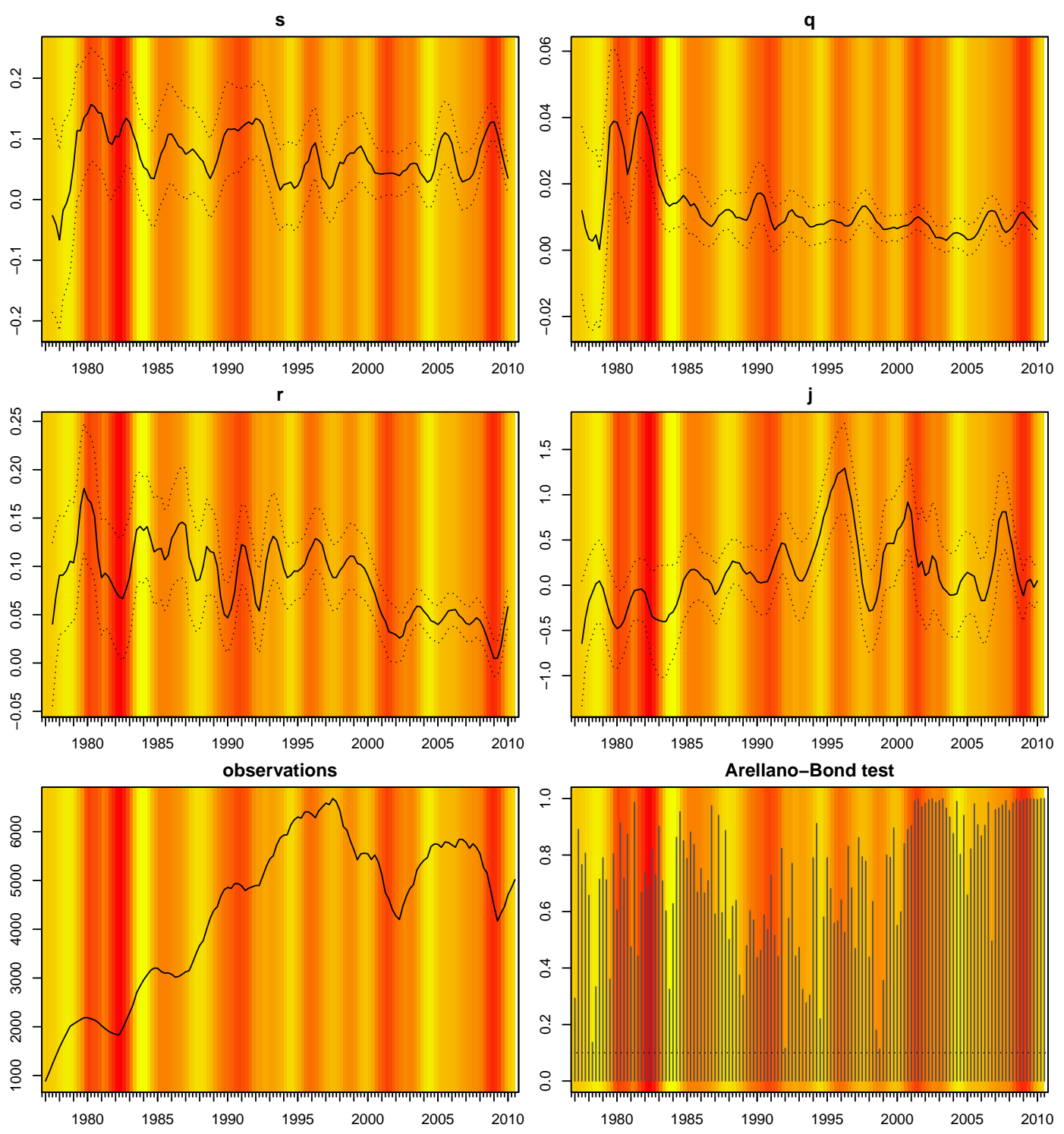

Figure 4: Regression results for the two-step System GMM estimation of (20) with $L=4$

the coefficient is mostly insignificant. ${ }^{17}$

As illustrated in the bottom-left panel, the number of observations used for the recursive regressions with a window of 5 quarters increases until late 1990s from around 1,000 to more than 6,000 and fluctuates thereafter between 4,000 and 6,000. Note the obvious cyclical pattern of the number of observations. In times of low business confidence, less observa-

\footnotetext{
${ }^{17}$ We estimated specifications excluding the cost of capital which, however, did not change the results. Also using a different measure for the cost of capital based on the ratio between interest payments and stock of debt as a proxy for the interest rate of the firm (cf. Dwenger 2010) did not yield very different results.
} 
tions are available. This is because we removed firm-years with negative cash flows which unsurprisingly arise especially in times of stagnation.

The Arellano-Bond test fails to reject the null hypothesis of no second-order serial correlation in the residuals at any reasonable level of significance for all time windows considered.

\subsection{Supply and demand conditions on the capital market over the cycle}

Supply and demand conditions on the capital market are characterized by the relative size of the effect of demand and cash flow on investment. Assuming the intercept parameters $\alpha_{1}, \alpha_{2}, \omega_{1}$ and $\omega_{2}$ to be constant, (15), (16) and (17) predict an inverse relationship between demand and cash-flow effects on investment.

We can therefore use the scatter plot depicted in Figure 5 as a guidance for identifying how relative supply and demand conditions on the capital market affect investment. Figure 5 plots the cyclical element of the demand effect on investment against the cyclical elements of the cash-flow effect for each quarter with the color intensity indicating the negative business confidence. ${ }^{18}$ A large (low) demand effect associated with a low (large) cash-flow effect suggests demand constraints to be more (less) important than credit constraints. As expected, an inverse relationship between relative demand and cash-flow effects can be observed. The interesting question is what quadrants quarters of economic distress are located in.

Times of crisis and stagnation are concentrated in the right quadrants which implies that, during such times, demand shocks have typically large effects on investment. Most of these quarters are located in the second quadrant meaning that investment was driven by demand considerations rather than credit market tightening. Further, it seems that it is mostly times of expansion during which investment is driven by supply conditions as compared to demand conditions. Also note that the recession in the late 1970s/early 1980s is very peculiar in the sense that it featured both large demand and cash-flow effects.

Let us now study the US business cycles in greater detail. The moderate downturn of investment in the recession in 1980 is associated with both a high sensitivity of investment to both demand, reflected by sales growth and Tobin's $q$, and cash flow which indicates pronounced shocks to the intercept parameters $\alpha_{1}, \alpha_{2}, \omega_{1}$ and $\omega_{2}$. Given the sharp rise of interest rates under Volker, these disruptions are not surprising. The supply and demand conditions prevailing on the capital market, however, cannot be interpreted in the context of our model. For the subsequent recession in 1982, we find that the slope of the supply curve, $\beta_{1}$, was high compared to the slop of the demand curve, $\beta_{2}$. Hence, the estimated coefficients indicate investment to be driven by the demand side rather the supply side as the demand-related coefficients move upwards whereas the cash flow's coefficient drops. Credit

\footnotetext{
${ }^{18}$ The demand effect is the average of the effect of sales growth and the adjusted effect of Tobin's $q$. The time-varying coefficient for Tobin's $q$ has been adjusted such that its variance is equal to the variance of the sales growth's coefficient. Since a considerable share of each of the time-varying coefficients is determined by factors independent of the business cycle, we use for the construction of the relative demand and cash-flow effects the cyclical components of the coefficients by applying an HP-filter $(\lambda=1,600)$ to the unfiltered coefficients estimated.
} 


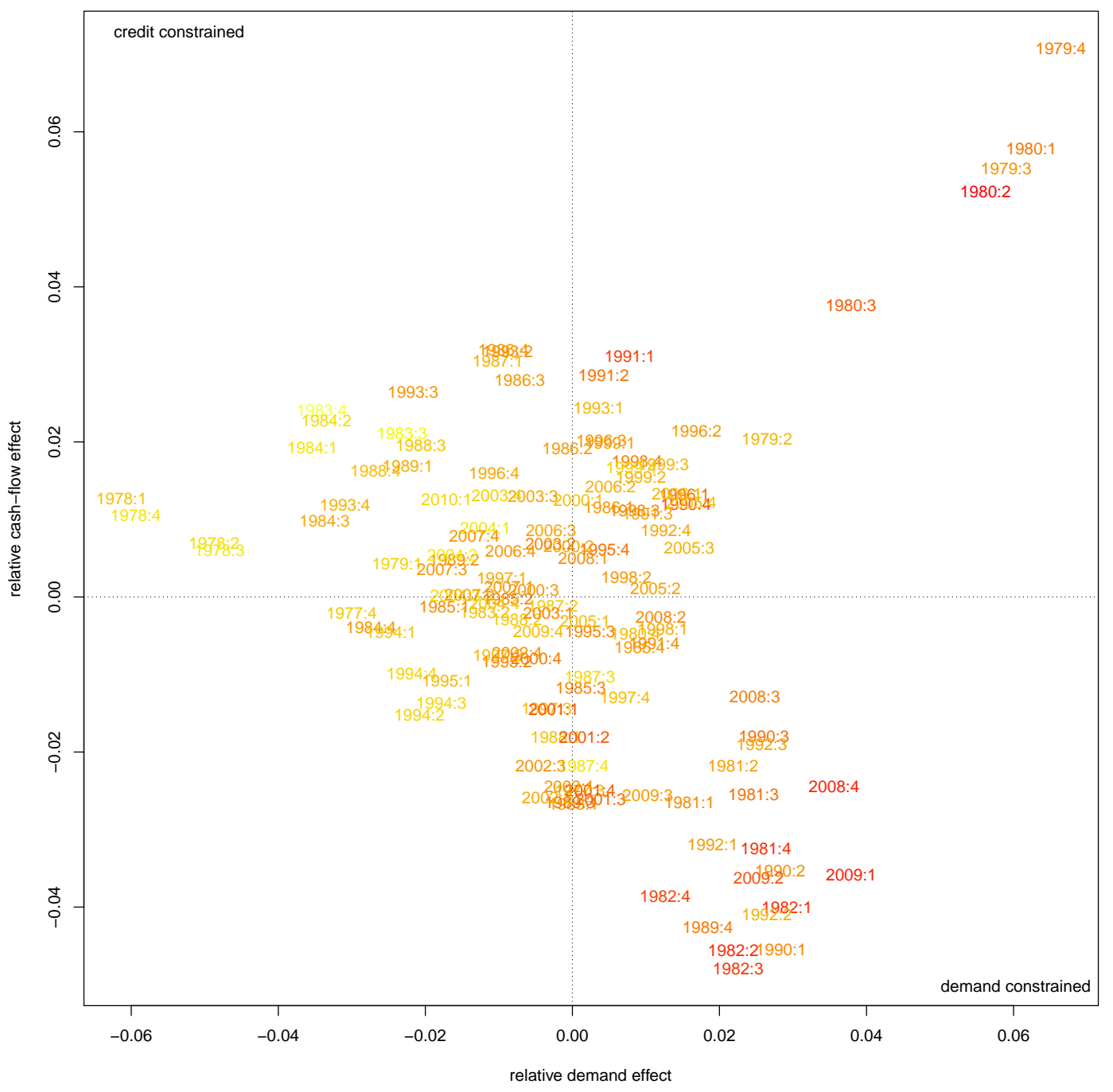

Figure 5: Demand effects vs. cash-flow effects on investment

constraints on capital expansion seem to become relatively more important in the following upswing.

The drops in the accumulation rate observed in the mid 1980s and early 1990s are both associated with increases in the demand effects on investment (especially sales growth) and an ambiguous behavior of the cash-flow effect. Again both periods of economic stagnation seem to have been caused by a lack of demand and deteriorating demand expectations. It seems that credit constraints become important at the end of both downturns.

The rest of the 1990s is, in general, a period of rising capital accumulation. Yet expansion slows down slightly in 1995 and 1998. Again, sales growth becomes relatively more important 
in predicting investment expenses. Interestingly, the coefficient of Tobin's $q$ spikes upwards between the two periods of stagnation. The slowdown of accumulation may also have been enforced by tightening credit constraints as indicated by rising cash-flow effects.

The decline of business investment after the burst of the dot-com bubble in 2001 is associated with low demand and cash-flow effects on investment.

The crisis following the financial meltdown in 2007 clearly indicates investment to be driven by inferior demand rather than credit-market conditions as demand effects on investment are large while cash-flow effects are low. In contrast to Mason (2012), we do not even find a strong cash-flow sensitivity of investment during the first stage of the downturn. Yet, his core result that credit constraints did not contribute considerably to the decline in investment overall is consistent with our finding.

\section{$6 \quad$ Fiscal and monetary policy in the US in the context of the capital market conditions identified}

Using the development of business investment and the estimated elasticities of investment with respect to demand and access to credit, one can assess the historical monetary and fiscal policy measures conducted to manage demand and the flow of credit. Before doing so, however, it is useful to briefly review the fiscal and monetary policy stance for the period under consideration.

\subsection{Management of aggregate demand and credit flows}

The first panel in Figure 6 depicts the federal funds rate which has traditionally been the main instrument used by the FED to stabilize demand, apart from the intermezzo in the early 1980s when the Reagan administration sought to target the money supply instead of the short term interest rate. Apart from the recession in the mid 1970s, when the nominal interest (but also inflation) was still high during the downturn, the monetary instrument usually spiked before the recession and dropped sharply during the downturn.

A quantitative assessment of the fiscal effort relative to the severity of the economic downturn is a challenging endeavor as government spending directly affects GDP and, hence, the measure one would like to normalize the fiscal effort on. The challenge is to relate the indicator of the fiscal effort to a measure of the deepness of the recession which is independent of the fiscal indicator used. We consider three measures plotted in the second to fourth panel of Figure 6.

First, a rough approximation but still fairly insightful measure is the percentage deviation of actual GDP from potential GDP as reported by the US Bureau of Economic Analysis (BEA), i.e. the relative output gap. As long as there is no crowding out of private spending by public spending, the relative output gap indicates the extent by which the public sector fails to to compensate the downturn of private demand. Yet, the assumption of no crowding out may be too restrictive. Hence, we consider two more measures which are highly robust to crowding out. 

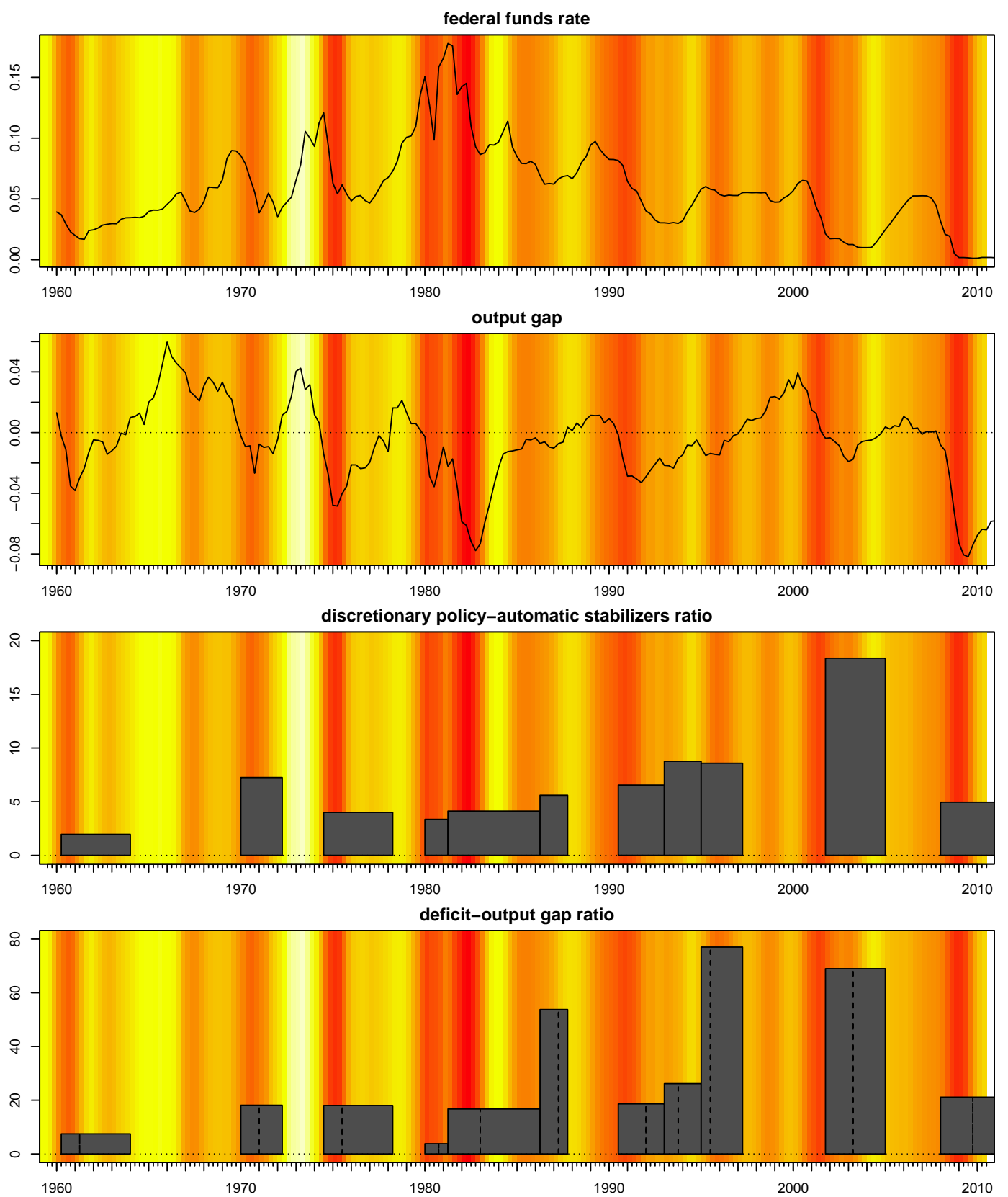

Figure 6: Indicators for monetary and fiscal efforts to stabilize aggregate demand (Sources: FED, BEA, own calculations)

Second, we consider, for each period of consecutive years with negative output gaps since the 1960s, a proxy for the ratio between the part of the primary fiscal deficit arising from 
discretionary policy and the part arising from the automatic stabilizers. ${ }^{19}$ This measure of the relative fiscal policy stance takes into account to some extent the aforementioned identification issue of the relative fiscal policy effort since the denominator of the ratio which captures the deepness of the recession is not directly affected by the numerator but only to the second order (through GDP).

Since our separation of the primary deficit into a discretionary and an automatic part relies on the assumption of the automatic stabilizers only affecting government revenues, we finally consider the ratio between the real primary deficit cumulated over the period of economic stagnation and the real negative output gap as an average from the beginning of the period to the trough, i.e. the maximum negative output gap. This measure approximates the relative fiscal effort as long as the deficits until the trough do not affect the economic downturn too much. Of course, this is a strong assumption but as the trough is usually reached within only a few quarters, the bulk of the fiscal policy measures, especially those with a strong delay, may affect the recovery rather than the downturn. ${ }^{20}$

As can be seen in the lower three panels of Figure 6, the fiscal effort measures are broadly consistent with each other. The trend of the discretionary policy-automatic stabilizers ratio reveals that fiscal stimulus packages became increasingly important in fighting recessions as compared to automatic stabilizers. Also the deficit-average downturn output gap ratio exhibits an increasing trend which, however, is not easy to interpret. It may be due to the way the ratios have been computed and the fact that the economy is growing.

Apart from the reserve-targeting experiment in the late 1970s and early 1980s, the Fed used the short-term interest rate as the primary target of monetary policy since the 1970s. To some extent, interest rate targeting in itself implies a mechanism of sustaining the flow of credit by providing the required short-term liquidity to financial institutions. A moderate positive demand shock for and/or negative supply shock of reserves put upwards pressure on the federal funds rate which is the rate on the market for reserves held at the Fed by depository institutions. Conducting outright or temporary open market operations, i.e. buying Treasury bills from its primary dealers, the Fed can increase the supply of reserves in the market to meet the increased relative demand.

As an additional safety valve, depository institutions may directly lend from the Fed to meet their reserve requirements through the discount window. This is a very effective way to provide short-term liquidity to the banking sector in case of sudden shifts in demand and

\footnotetext{
${ }^{19}$ Assuming that the automatic stabilizers only affect government revenues, the primary deficit arising from discretionary policy is computed as the difference between government expenditures and the cyclically adjusted government revenues. The primary deficit arising form automatic stabilizers is then simply the difference between government revenues and the cyclically adjusted government revenues. Data has been obtained from the BEA.

${ }^{20}$ Note that the last two measures have been computed for each sub-cycle which is the period between two local maxima of the output gap with all values being negative. The trough of a sub-cycle is defined as the minimum output gap in that period. Hence, the downturn is the part of the sub-cycle which features a decreasing output gap whereas the output gap is increasing in the recovery. Note that the downturn starts not necessarily when the output gap starts falling but when it becomes negative. Equivalently, the recovery ends when the output gap becomes positive and not necessarily when the next downturn starts, i.e. when the output gap starts falling again. This is in order to have the two measures as comparable as possible.
} 
supply as was the case, for instance, after the terrorist attacks in September 2001 and after the bankruptcy of Lehman Brothers in September 2008.

\subsection{Assessing fiscal and monetary policy measures}

According to our results, the decline of investment during the second part of the double-dip recession in the early 1980s was caused by adverse demand conditions relative to supply conditions with the relevant quarters being located deep in the second quadrant in Figure 6 , respectively. At the same time the low discretionary policy-automatic stabilizers ratio suggests that fiscal policy under the Reagan administration relied primarily on automatic stabilizers rather than discretionary expansionary policy which may have contributed to the rather long duration of the economic stagnation. Overall, the fiscal effort was lower than during the succeeding recessions. The deficit-output gap ratio suggests that the second part of the recession involved more fiscal efforts than the first one. Given the high elasticity of investment with respect to demand, a more active demand management would have likely had considerable marginal effects and might have reduced the decline of investment.

The relative fiscal efforts during the recession in the early 1990s as a consequence of the S\&L crisis were rather large compared to previous downturns as can be read from Figure 6. The mild recession in the early 1990s was mainly fought by increasing benefits for unemployeds and coincided with a fiscal expansion due to the First Gulf War. To maintain the flow of credit during the S\&L crisis in the late 1980s and early 1990s, the Fed conducted monetary policy known as quantitative policy by which corporate bonds as well as mortgagebacked securities were purchased by the Fed in order to inject liquidity to the banking sector. The latter measures might have been successful in providing businesses with credit, whereas the demand management might not have been timely enough as firms faced inferior demand conditions during the downturn.

The respective relative capital market conditions during the slowdowns of expansion in the mid and late 1990s are difficult to categorize. According to the scatter plot in Figure 5, the credit market conditions seem to have been more important than demand conditions.

The recession following the dot-com bubble is difficult to interpret as neither demand related nor supply related variables seem to have had strong effects on investment. Policy attempts to stimulate demand and the flow of credit in order to stabilize investment may have been either effective or ineffective as both scenarios are consistent with the coefficients observed. Note, however, that the fiscal policy measures have been enormous. ${ }^{21}$ Nevertheless, business investment dropped tremendously indicating that these measures were not particularly successful. Again it is the early recovery which seems to experience relatively tight credit markets.

We obtain an unambiguous result for the recent recession following the financial meltdown beginning in 2007: investment was much more impeded by the demand side than by

\footnotetext{
${ }^{21}$ The Bush administration taking over in 2001 started off with major tax cuts such as the Economic Growth and Tax Relief Reconciliation Act of 2001, the Job Creation and Worker Assistance Act of 2002 and the Jobs and Growth Tax Relief Reconciliation Act of 2003. On the spending side, the wars in Afghanistan (started in 2001) and in Iraq (started in 2003) implied a significant fiscal expansion.
} 
the supply side. Only in the early recovery, the economy moved into credit constraints. According to the policy measures depicted in Figure 6, the relative fiscal policy effort has been far below trend in the recent economic crisis. Taking into account the fact that the potential output has been revised downwards considerably after 2007, the figures for the current recession overstate the fiscal policy effort. The relative fiscal expansion is moderate despite two major stimulus packages launched by the US government. ${ }^{22}$ Nevertheless, these measures were only moderate given the speed and extent of the downturn which has been argued by many Keynesian economists and is confirmed by the plots in Figure 6 .

Since the federal funds rate hit the zero lower bound by the end of 2008 and the economy responded too slowly to the declining short-term interest rate, the Fed made excessive use of unconventional monetary policy through existing as well as newly created, temporary lending facilities. ${ }^{23}$

It is not implausible to argue that the observed coefficients for the recent economic downturn are the result of the adverse weights given to the management of demand and the management of credit flows. It seems that the policy measures taken were sufficient to eliminate credit constraints but insufficient to stabilize investment through raising aggregate demand and stimulating demand expectations. Hence the decline of investment starting in 2008 is due to a lack of demand management rather than attempts to maintain the access to credit. Yet, as sales and utilization increased and expectations improved out of the recession, credit constraints became binding for an increasing number of firms.

\footnotetext{
${ }^{22}$ The Economic Stimulus Act of 2008 involved $\$ 168$ billion in tax rebates for consumers and businesses. The second major stimulus package was implemented by the $\$ 787$ billion American Recovery and Reinvestment Act of 2009 which mainly included tax reliefs, funding for states and public investment in infrastructure, health and education.

${ }^{23}$ First, the Fed extended its balance sheet to raise the monetary base and provide liquidity (quantitative easing), growing from $\$ 869$ billion in August 2008 to $\$ 2,882$ billion in July 2011. The balance sheet expansion from August 2008 to March 2009 was driven by short-term loans to the banking sector as well as to institutions in key credit markets. Since depository institutions avoided borrowing through the discount window due to its stigma of bank failure, the Fed introduced the Term Auction Facility in December 2007 to provide shortterm liquidity to banks without revealing their identity. In March 2008, the Fed announced the Primary Dealer Credit Facility through which the central bank lent out directly to primary dealers which was not permitted before. The Term Asset-Backed Securities Loan Facility announced in November 2008 aimed at stimulating consumer and business credit lending by granting loans against the collateral of asset-backed securities backed by recently issued consumer and business loans. After March 2009, the balance sheet expansion mainly reflected purchases of Treasury, agency and agency-guaranteed securities. Second, the central bank shifted its portfolio towards riskier assets (qualitative easing) to take out risk from financial institutions' balance sheets to foster private lending. The Term Securities Lending Facility implemented in March 2008 was aimed at increasing the liquidity of the banking sector by allowing primary dealers to switch illiquid debt for tradable government securities with the Fed. From November 2008 to November 2009, the Fed purchased $\$ 175$ billion of government-sponsored enterprise debt as well as $\$ 1,250$ billion of mortgagebacked securities. In March 2009, the Fed started buying longer-term Treasury securities for $\$ 300$ billion, followed by a second round of purchasing Treasury securities for $\$ 600$ billion. To keep credits flowing, both the Fed and the Treasury guaranteed private assets and loans. For instance, the Temporary Liquidity Guarantee Program involved a $\$ 1.4$ billion guarantee on senior subordinated debt and poorly performing assets by banks as well as on non-interest bearing deposit accounts. One major attempt of the US government to sustain the flow of credit was the Emergency Economic Stabilization Act of 2008 which enabled the government to spend up to $\$ 700$ billion to purchase troubled bank assets in order to strengthen the banks' balance sheets.
} 


\section{Concluding remarks}

The policy makers' emphasis of measures aimed at maintaining the flow of credit from the banking sector to the private sector in order to overcome times of economic depression is theoretically well founded in the conventional literature on investment theory and informational economics.

This paper seeks to contribute empirically to the question what factors drive investment over the business cycle. It sets out with a simple model of investment which motivates supply and demand conditions on the capital market. According to conventional wisdom, credit markets tighten during economic downturns not allowing firms to invest despite promising investment opportunities. A different take is that during recessions firms are not willing to invest even though they face good conditions by which they can obtain external finance. We empirically study the relative importance of supply and demand conditions on the capital market over the cycle.

Following the convention in the empirical investment literature, investment opportunities are approximated by the growth rate of sales and Tobin's $q$ whereas the finance constraints are reflected by the internal flow of cash.

To assess the relative tightness of supply and demand conditions on the capital market for corporate non-financial businesses in the US since 1977, a dynamic investment model including sales growth, Tobin's $q$, cash flow and the cost of capital as covariates has been estimated using firm-level data obtained from Compustat. As we are interested in the cyclical behavior of the covariates' contributions to explaining investment, we estimate time-varying coefficients by applying a rolling window regression with a size of five quarters. Since the econometric model of investment is dynamic, we use the System GMM estimator developed by Arellano and Bover (1995) and Blundell and Bond (1998).

We find that the investment elasticities of the demand variables, i.e. sales growth and Tobin's $q$, are in general highly counter-cyclical. Overall, demand constraints seem to be crucial factors contributing to the slowdown of accumulation in times of economic distress relative to credit market conditions. In contrast to the prediction of the financial accelerator literature that credit constraints tighten in the downturn (relative to demand constraints) as net worth deteriorates, the cash-flow coefficient does not exhibit a clear counter-cyclical pattern.

We further find that the most tremendous declines in business investment which occurred in the contexts of the recessions in 1982, 1990, 2001 and 2008/09 were driven by the demand side of the capital market rather than the supply side since, during these times, an improvement of investment opportunities reflected by an expansion of sales growth and Tobin's $q$, on average, induced firms to raise investment to a disproportionately large extent whereas an easing of credit constraints, on average, provoked only a disproportionately small expansion of investment.

These findings do not imply that credit constraints are irrelevant in practice. In fact, during the slight slow-downs of economic expansion in 1985, 1995 and 1998 firms seem to have faced tight credit constraints compared to demand constraints. Moreover, during the early recoveries after the 1982, 1990, 2001 and 2008/09 recessions, the cash-flow coefficients 
rise indicating a tightening of credit constraints. Given the large efforts of US monetary and fiscal policy to maintain the flow of credit during deep recessions as reviewed in the present paper, low cash-flow coefficients may indicate that these policy measures have been successful in preventing credit crunches.

Yet, the high elasticities of investment with respect to sales growth and Tobin's $q$ may reflect an insufficient use of measures aimed at stabilizing aggregate demand and expectations during times of economic distress. Only during the 2001 recession which is associated with the largest relative fiscal effort that we measure, the demand effects on investment did not unambiguously rise.

Of particular interest is the recent recession in 2008/09 following the financial meltdown which has been answered by dramatic policy intervention such as the creation of special lending facilities as well as government purchases and guaranties of troubled assets all of which were mainly aimed at ensuring the liquidity of the banking sector. At the same time, the fiscal stimuli packages have been criticized by economists as being small which is also confirmed by our measures of the relative fiscal effort. The adverse usage of demand management tools and credit flow tools may also be reflected by the coefficients of the investment function during the economic downturn. Large demand and low cash-flow effects characterize the recession and indicate demand rather than credit constraints to investment. 


\section{References}

Abel, A. B., Blanchard, O. J. (1986): Investment and sales: some empirical evidence, Working Paper 2050, National Bureau of Economic Research.

Abel, A. B., Eberly, J. C. (2011): How Q and Cash Flow Affect Investment without Frictions: An AnalyticExplanation, The Review of Economic Studies.

Ahn, S. C., Schmidt, P. (1995): Efficient estimation of models for dynamic panel data, Journal of Econometrics, 68(1), pp. 5-27.

Arellano, M., Bond, S. (1991): Some Tests of Specification for Panel Data: Monte Carlo Evidence and an Application to Employment Equations, Review of Economic Studies, 58(2), pp. 277-97.

Arellano, M., Bover, O. (1995): Another look at the instrumental variable estimation of error-components models, Journal of Econometrics, 68(1), pp. 29-51.

Bernanke, B. S., Gertler, M. (1989): Agency Costs, Net Worth and Business Fluctuations, The American Economic Review, 79(1), pp. 14-31.

Blundell, R., Bond, S. (1998): Initial conditions and moment restrictions in dynamic panel data models, Journal of Econometrics, 87(1), pp. 115-143.

Blundell, R., Bond, S., Windmeijer, F. (2000): Estimation in dynamic panel data models: improving on the performance of the standard GMM estimator, IFS Working Papers W00/12, Institute for Fiscal Studies.

Chirinko, R. S., Fazzari, S. M., Meyer, A. P. (1999): How responsive is business capital formation to its user cost?: An exploration with micro data, Journal of Public Economics, 74(1), pp. 53-80.

Christiano, L., Eichenbaum, M., Rebelo, S. (2009): When is the government spending multiplier large?, NBER Working Papers 15394, National Bureau of Economic Research.

Chung, K. H., Pruitt, S. W. (1994): A Simple Approximation of Tobin's q, Financial Management, 23(3), pp. 70-4.

Cogan, J. F., Cwik, T., Taylor, J. B., Wieland, V. (2010): New Keynesian versus old Keynesian government spending multipliers, Journal of Economic Dynamics and Control, $34(3)$, pp. 281-295.

Dwenger, N. (2010): User cost elasticity of capital revisited.

Eisner, R. (1960): A Distributed Lag Investment Function, Econometrica, 28(1), pp. 1-29.

Erickson, T., Whited, T. M. (2000): Measurement Error and the Relationship between Investment and q, Journal of Political Economy, 108(5), pp. 1027-1057. 
Fazzari, S. M., Athey, M. J. (1987): Asymmetric Information, Financing Constraints, and Investment, The Review of Economics and Statistics, 69(3), pp. 481-87.

Fazzari, S. M., Hubbard, R. G., Petersen, B. C. (1988): Financing Constraints and Corporate Investment, Brookings Papers on Economic Activity, 1988(1), pp. 141-206.

Fazzari, S. M., Hubbard, R. G., Petersen, B. C. (2000): Investment-cash flow sensitivities are useful: a comment on Kaplan and Zingales, The Quarterly Journal of Economics, pp. 695-705.

Gertler, M., Hubbard, R. G. (1988): Financial Factors in Business Fluctuations, Financial market volatility: Causes, consequences, and policy recommendations. Federal Reserve Bank of Kansas City, pp. 33-71.

Gilchrist, S., Zakrajsek, E. (2007): Investment and the Cost of Capital: New Evidence from the Corporate Bond Market, NBER Working Papers 13174, National Bureau of Economic Research, Inc.

Greenwald, B., Stiglitz, J. E., Weiss, A. (1984): Informational Imperfections in the Capital Market and Macroeconomic Fluctuations, The American Economic Review, 74(2), pp. 194-9.

Gugler, K., Mueller, D. C., Yurtoglu, B. B. (2004): Marginal q, Tobin's q, Cash Flow, and Investment, Southern Economic Journal, 70(3), pp. 512-31.

Hayashi, F. (1982): Tobin's Marginal $q$ and Average $q$ : A Neoclassical Interpretation, Econometrica, 50(1), pp. 213-24.

Jensen, M. C., Meckling, W. H. (1976): Theory of the Firm: Managerial Behavior, Agency Costs, and Ownership Structure, Journal of Financial Economics, 3(4), pp. 305-60.

Kaplan, S. N., Zingales, L. (1997): Do investment-cash flow sensitivities provide useful measures of financing constraints?, The Quarterly Journal of Economics, 112(1), pp. 169215 .

Lindenberg, E. B., Ross, S. A. (1981): Tobin's $q$ Ratio and Industrial Organization, Journal of Business, 54(1), pp. 1-32.

Mason, J. W. (2012): Was Restricted Credit Responsible for the Fall in Investment During the Great Recession?

Myers, S. C., Majluf, N. S. (1984): Corporate Financing and Investment Decisions when Firms Have Information That Investors Do Not Have, Journal of Financial Economics, 13(2), pp. 187-221.

Romer, C., Bernstein, J. (2009): The Job Impact of the American Recovery and Reinvestment Plan, Tech. rep. 
Schoder, C. (forthcoming): Demand, q, financial constraints and shareholder value revisited: an econometric micro-analysis of US fixed investment, International Journal of Economics and Business Research.

Tobin, J. (1969): A General Equilibrium Approach to Monetary Theory, Journal of Money, Credit and Banking, 1(1), pp. 15-29. 
Table 1: Variable definitions and data sources

\begin{tabular}{|c|c|}
\hline$g$ & $\begin{array}{l}\text { net property, plant and equipment } * 100 / \text { GDP deflater / lag[net property, } \\
\text { plant and equipment } * 100 / \text { GDP deflater] - } 1\end{array}$ \\
\hline$s$ & $\begin{array}{l}\text { (sales - depreciation) } * 100 / \text { GDP deflater / lag[(sales - depreciation) } * \\
\text { 100/GDP deflater }-1\end{array}$ \\
\hline$q$ & $\begin{array}{l}\text { lag[quarterly market price of shares } * \text { common shares outstanding }+ \text { total } \\
\text { liabilities] / lag[total assets] }\end{array}$ \\
\hline$r$ & $\begin{array}{l}\text { income before extraordinary items * 100/GDP deflater / lag[net property, } \\
\text { plant and equipment } * 100 / \text { GDP deflater }]\end{array}$ \\
\hline$j$ & $\begin{array}{l}\text { Baa bond rate }+(\text { equity beta } *(1-\operatorname{lag}[\text { total liabilities / total assets }])) * \\
(\text { Baa bond rate }- \text { Aaa bond rate })\end{array}$ \\
\hline
\end{tabular}

\section{A Data}

All firm-level data have been obtained from the Compustat North America Fundamentals (monthly updated) database. The quarterly GDP deflater has been taken from the BEA, NIPA Table 1.1.4. The variables used in the regressions have been constructed as reported in Table 1.

The following screening procedure has been applied to the data: First, we removed observations with implausible realizations in any variable. In particular, we eliminated observations with (a) a non-positive lagged capital stock, (b) non-positive total assets and (c) non-positive sales.

Second, from the remaining set we excluded outliers by trimming off the $1 \%$ and $99 \%$ quantiles of each variables' distribution which is common in the literature (cf. Chirinko et al. 1999; Gugler et al. 2004).

Third, observations with accumulation rates above 1 or below -1 have been eliminated in order to further reduce the influence of extreme values. Since we are interested in the question how credit constraints vary over time and over the cycle, observations with a non-positive cash-flow are removed.

Fourth, we excluded firms that were subject to major mergers and acquisitions. We eliminated all firms for whom M\&A data are available and which had M\&A's of more than $20 \%$ of their net capital stock. This is in compliance with the literature (cf. Fazzari et al. 1988).

Fifth, in order to condense the data set, any observation whose realization of the accumulation rate was not part of a at least 5-quarters long sequence of realizations of the accumulation rate has bee removed. Further, observations with a missing value for the accumulation rate which is the main dependent variable have been eliminated. From the remaining set, we only included firms with realizations in the accumulation rate for at least five consecutive quarters.

Finally, very large firms with a mean of real total assets exceeding $\$ 30,000$ (which is roughly $1 \%$ of all firms) have been eliminated. 


\section{B One-step and two-step GMM estimator}

This section outlines the one-step and two-step GMM estimators of the parameters of a linear model as well as estimators for parameter variances which are robust to heteroskedasticity and serial correlation in the disturbance terms.

Let us consider a general linear model of the form

$$
\mathbf{y}=\mathbf{X}^{\prime} \beta+\varepsilon
$$

where the $(N \times 1)$ dimensional vector $\mathbf{y}$, the $(k \times N)$ dimensional matrix $\mathbf{X}$ and the $(N \times 1)$ dimensional vector of disturbance terms $\varepsilon$ are realizations of the random variables $y, x_{1} \ldots x_{k}$ and $\varepsilon$, respectively. $\beta$ is a $(1 \times k)$ dimensional parameter-vector. To ensure identification of this model, we assume

$$
\mathrm{E}[\varepsilon \mid \mathbf{Z}]=\mathbf{0}
$$

where $\mathbf{Z}$ is a $(j \times N)$ dimensional matrix of realizations of instruments $z_{1} \ldots z_{j}$ with $j \geq k$.

Minimizing

$$
\frac{1}{N} \hat{\varepsilon}^{\prime} \mathbf{Z} \mathbf{A} \mathbf{Z}^{\prime} \hat{\varepsilon}
$$

where $\mathbf{A}$ is a symmetric $(k \times k)$ matrix weighting the moment conditions yields an estimator for $\beta$,

$$
\hat{\beta}_{\mathbf{A}}=\left(\mathbf{X}^{\prime} \mathbf{Z} \mathbf{A} \mathbf{Z}^{\prime} \mathbf{X}\right)^{-1} \mathbf{X}^{\prime} \mathbf{Z} \mathbf{A} \mathbf{Z}^{\prime} \mathbf{y} .
$$

One can show that the asymptotic variance of this estimator is

$$
\operatorname{Avar}\left[\hat{\beta}_{\mathbf{A}}\right]=\left(\boldsymbol{\Sigma}_{\mathbf{Z X}}^{\prime} \mathbf{A} \boldsymbol{\Sigma}_{\mathbf{Z X}}\right)^{-1} \boldsymbol{\Sigma}_{\mathbf{Z X}}^{\prime} \mathbf{A} \operatorname{Var}[\mathbf{z} \varepsilon] \mathbf{A} \boldsymbol{\Sigma}_{\mathbf{Z X}}\left(\boldsymbol{\Sigma}_{\mathbf{Z X}}^{\prime} \mathbf{A} \boldsymbol{\Sigma}_{\mathbf{Z X}}\right)^{-1}
$$

where $\boldsymbol{\Sigma}_{\mathbf{Z X}}=\operatorname{plim}_{N \rightarrow \infty} \frac{1}{N} \mathbf{Z}^{\prime} \mathbf{X}$.

Efficiency of the GMM estimator in (25) depends on the right choice of A. More weight should be given to moments with low variance and covariances. One can show that the estimator in (25) is efficient if $\mathbf{A}=\operatorname{Var}[\mathbf{z} \varepsilon]^{-1}$. Yet, $\operatorname{Var}[\mathbf{z} \varepsilon]$ is unknown in general which renders the estimator infeasible.

To derive a feasible efficient estimator note first that $\operatorname{Var}[\mathbf{z} \varepsilon]=\operatorname{plim}_{N \rightarrow \infty} \frac{1}{N} \mathrm{E}\left[\mathbf{Z}^{\prime} \Omega \mathbf{Z}\right]$ where $\boldsymbol{\Omega} \equiv \mathrm{E}\left[\varepsilon \varepsilon^{\prime} \mid \mathbf{Z}\right]$. Now a (not necessarily consistent) estimate for $\boldsymbol{\Omega}$, i.e. $\hat{\boldsymbol{\Omega}}=\hat{\varepsilon} \hat{\varepsilon}^{\prime}$, has to be computed with the property that $\frac{1}{N} \mathbf{Z}^{\prime} \hat{\mathbf{\Omega} Z} \mathbf{Z}$ is a consistent estimate for $\operatorname{Var}[\mathbf{z} \varepsilon]$. The residuals which meet this requirement can be obtained from any consistent estimator of $\beta$. In practice, the weighting matrix $\mathbf{A}=\left(\mathbf{Z}^{\prime} \mathbf{H Z}\right)^{-1}$ is chosen for an initial estimate where $\mathbf{H}$ is an approximation of $\boldsymbol{\Omega}$ based on the assumption of spheric disturbances, which gives rise to the one-step GMM estimator,

$$
\hat{\beta}_{\text {one-step }}=\left(\mathbf{X}^{\prime} \mathbf{Z}\left(\mathbf{Z}^{\prime} \mathbf{H} \mathbf{Z}\right)^{-1} \mathbf{Z}^{\prime} \mathbf{X}\right)^{-1} \mathbf{X}^{\prime} \mathbf{Z}\left(\mathbf{Z}^{\prime} \mathbf{H} \mathbf{Z}\right)^{-1} \mathbf{Z}^{\prime} \mathbf{y} .
$$


The residuals of this estimator are then used to construct $\hat{\Omega}$ which is used for the two-step GMM estimator which is feasible and efficient,

$$
\hat{\beta}_{\text {two-step }}=\left(\mathbf{X}^{\prime} \mathbf{Z}\left(\mathbf{Z}^{\prime} \hat{\mathbf{\Omega}} \mathbf{Z}\right)^{-1} \mathbf{Z}^{\prime} \mathbf{X}\right)^{-1} \mathbf{X}^{\prime} \mathbf{Z}\left(\mathbf{Z}^{\prime} \hat{\mathbf{\Omega}} \mathbf{Z}\right)^{-1} \mathbf{Z}^{\prime} \mathbf{y} .
$$

While the parameter estimates of the one-step and two-step procedure are consistent for any choice of $H$ based on the assumption of spherical disturbances, this does not hold for the variance estimator specified in (26) as, in general, $\mathbf{Z}^{\prime} \mathbf{H Z}$ is not a consistent estimator for $\operatorname{Var}[\mathbf{z} \varepsilon]$. Hence, the standard errors derived from this estimate would not be robust to heteroskedasticity and auto-correlation in the disturbances.

For the one-step estimator, a robust variance estimator can be obtained by approximating $\operatorname{Var}[\mathbf{z} \varepsilon]$ in (26) by $\frac{1}{N} \mathbf{Z}^{\prime} \hat{\mathbf{\Omega} Z} \mathbf{Z}$ which is a consistent estimate of the former. The residuals for computing $\hat{\Omega}$ are obtained from the one-step estimator using $\mathbf{A}=\left(\mathbf{Z}^{\prime} \mathbf{H} \mathbf{Z}\right)^{-1}$. The robust variance estimator is

$$
\widehat{\operatorname{Avar}}\left[\hat{\beta}_{\text {one-step }}\right]=\left(\begin{array}{c}
\left(\mathbf{X}^{\prime} \mathbf{Z}\left(\mathbf{Z}^{\prime} \mathbf{H Z}\right)^{-1} \mathbf{Z}^{\prime} \mathbf{X}\right)^{-1} \mathbf{X}^{\prime} \mathbf{Z}\left(\mathbf{Z}^{\prime} \mathbf{H Z}\right)^{-1} \mathbf{Z}^{\prime} \hat{\mathbf{\Omega}} \times \\
\times \mathbf{Z}\left(\mathbf{Z}^{\prime} \mathbf{H} \mathbf{Z}\right)^{-1} \mathbf{Z}^{\prime} \mathbf{X}\left(\mathbf{X}^{\prime} \mathbf{Z}\left(\mathbf{Z}^{\prime} \mathbf{H Z}\right)^{-1} \mathbf{Z}^{\prime} \mathbf{X}\right)^{-1}
\end{array}\right)
$$

\section{System GMM estimator}

This section derives the System GMM estimator as proposed by Arellano and Bover (1995) and Blundell and Bond (1998). Let us consider a special case of the linear error components model in (22) which has the following form:

$$
\begin{aligned}
& y_{i, t}=\sum_{l=1}^{m} \alpha_{1, l} y_{i, t-l}+\sum_{l=0}^{m} \boldsymbol{\beta}_{2, l}^{\prime} \mathbf{x}_{i, t-l}+\sum_{l=0}^{m} \boldsymbol{\gamma}_{2, l}^{\prime} \mathbf{w}_{i, t-l}+\sum_{l=0}^{m} \boldsymbol{\delta}_{2, l}^{\prime} \mathbf{v}_{i, t-l}+u_{i, t} \\
& u_{i, t}=\mu_{i}+\varepsilon_{i, t}
\end{aligned}
$$

where the $k \times 1$ vector $\mathbf{x}_{i, t}$, the $p \times 1$ vector $\mathbf{w}_{i, t}$ and the $q \times 1 \mathbf{v}_{i, t}$ contain $k$ strictly exogenous, $p$ predetermined (but not strictly exogenous) and $q$ endogenous variables, respectively. $\mu_{i}$ are unobserved group specific fixed effects. Similar to Ahn and Schmitz's (1995) and Blundell and Bond's (1998) discussion of a dynamic AR(1) model, we assume that all observations are independently distributed across individuals as well as the following for $i=1, \ldots, N$ :

$$
\begin{aligned}
& \mathrm{E}\left[\mu_{i}\right]=\mathrm{E}\left[\varepsilon_{i, t}\right]=0 \text { for } t=m+1, \ldots, T \\
& \mathrm{E}\left[\mu_{i} \varepsilon_{i, t}\right]=0 \text { for } t=m+1, \ldots, T \\
& \mathrm{E}\left[\varepsilon_{i, t} \varepsilon_{i, s}\right]=0 \forall t \neq s \\
& \mathrm{E}\left[y_{i, 1} \varepsilon_{i, t}\right]=\ldots=\mathrm{E}\left[y_{i, m} \varepsilon_{i, t}\right]=0 \text { for } t=m+1, \ldots, T \\
& \mathrm{E}\left[\mathbf{x}_{i, 1} \varepsilon_{i, t}\right]=\ldots=\mathrm{E}\left[\mathbf{x}_{i, m} \varepsilon_{i, t}\right]=\mathbf{0} \text { for } t=m+1, \ldots, T \\
& \mathrm{E}\left[\mathbf{w}_{i, 1} \varepsilon_{i, t}\right]=\ldots=\mathrm{E}\left[\mathbf{w}_{i, m} \varepsilon_{i, t}\right]=\mathbf{0} \text { for } t=m+1, \ldots, T \\
& \mathrm{E}\left[\mathbf{v}_{i, 1} \varepsilon_{i, t}\right]=\ldots=\mathrm{E}\left[\mathbf{v}_{i, m} \varepsilon_{i, t}\right]=\mathbf{0} \text { for } t=m+1, \ldots, T
\end{aligned}
$$


Note that the AR process considered here which is of order $m$ and includes covariates other than the lagged dependent variable requires more initial conditions specified in (35)-(38) than are imposed by Ahn and Schmidt (1995). Under the assumptions made in (32)-(38) the idiosyncratic error terms $\Delta \varepsilon_{i, t}$ of (30) in first differences obviously satisfy the following set of orthogonality conditions for all $i=1, \ldots, N$ :

$$
\begin{aligned}
& \mathrm{E}\left[y_{i, s} \Delta u_{i, t}\right]=0 \quad \forall s \leq t-2 \text { with } t=m+2, \ldots, T_{i} \\
& \mathrm{E}\left[\mathbf{x}_{i, s} \Delta u_{i, t}\right]=\mathbf{0} \quad \text { for } s=1, \ldots, T_{i} \text { and } t=m+2, \ldots, T_{i} \\
& \mathrm{E}\left[\mathbf{w}_{i, s} \Delta u_{i, t}\right]=\mathbf{0} \quad \forall s \leq t-1 \text { with } t=m+2, \ldots, T_{i} \\
& \mathrm{E}\left[\mathbf{v}_{i, s} \Delta u_{i, t}\right]=\mathbf{0} \quad \forall s \leq t-2 \text { with } t=m+2, \ldots, T_{i}
\end{aligned}
$$

These moment conditions can be rewritten in compact form as

$$
\mathrm{E}\left[\mathbf{Z}_{i}^{d i f^{\prime}} \Delta \mathbf{u}_{i}\right]=0
$$

where

$$
\Delta \mathbf{u}_{i}=\left(\Delta \varepsilon_{i, m+2}, \Delta \varepsilon_{i, m+3}, \ldots, \Delta \varepsilon_{i, T_{i}}\right)^{\prime}
$$

is a $\left(T_{i}-m-1\right)$ vector comprising the idiosyncratic error terms of the first-differenced model and $\mathbf{Z}_{i}^{\text {dif }}$ is a block diagonal matrix, $\mathbf{Z}_{i}^{\text {dif }}=\operatorname{diag}\left[\mathbf{Z}_{i}^{\text {dif, }(m+2)}, \mathbf{Z}_{i}^{\text {dif, }(m+3)}, \ldots, \mathbf{Z}_{i}^{\text {dif, }\left(T_{i}\right)}\right]$, with

$$
\mathbf{Z}_{i}^{d i f,(t)}=\left(y_{i, 1}, \ldots, y_{i, t-2}, \mathbf{x}_{i, 1}^{\prime}, \ldots, \mathbf{x}_{i, T_{i}}^{\prime}, \mathbf{w}_{i, 1}^{\prime}, \ldots, \mathbf{x}_{i, t-1}^{\prime}, \mathbf{v}_{i, 1}^{\prime}, \ldots, \mathbf{x}_{i, t-2}^{\prime}\right)
$$

Using this instrument matrix, the one-step and two-step Difference GMM estimators can be derived as outlined in section B.

As argued by Blundell and Bond (1998), however, the level instruments used in the Difference GMM estimator are weak in two cases: first, if the processes driving the variables in $\mathbf{x}_{i, t}, \mathbf{w}_{i, t}$ and $\mathbf{v}_{i, t}$ are highly persistent; second, if the variance of the fixed effects compared to the variance of the idiosyncratic error term is large. This is because the information about any instrumented variable $\Delta \omega_{i, t}$ contained in the respective lags of $\omega_{i, t}$ used as instruments converges to zero as $\omega_{i, t}$ approaches a random walk process or as the relative variance of the fixed effects approaches infinity.

To raise the efficiency of the GMM estimator, Blundell and Bond (1998) and Blundell et al. (2000) derive the System GMM estimator by identifying an additional set of orthogonality conditions obtained from the equation in levels using as instruments the right-hand side variables in first differences. For the multivariate case considered here the moment conditions are, for all $i=1, \ldots, N$,

$$
\begin{aligned}
& \mathrm{E}\left[\Delta y_{i, t-1} u_{i, t}\right]=0 \text { for } t=m+2, \ldots, T_{i} \\
& \mathrm{E}\left[\boldsymbol{\Delta} \mathbf{x}_{i, t} u_{i, t}\right]=\mathbf{0} \text { for } t=m+1, \ldots, T_{i} \\
& \mathrm{E}\left[\boldsymbol{\Delta} \mathbf{w}_{i, t} u_{i, t}\right]=\mathbf{0} \text { for } t=m+1, \ldots, T_{i} \\
& \mathrm{E}\left[\boldsymbol{\Delta} \mathbf{v}_{i, t-1} u_{i, t}\right]=\mathbf{0} \text { for } t=m+2, \ldots, T_{i}
\end{aligned}
$$


which require that each of the variables contained in $\Delta y_{i, t}, \Delta \mathbf{x}_{i, t}, \Delta \mathbf{w}_{i, t}$ and $\Delta \mathbf{v}_{i, t}$ are uncorrelated with $\mu_{i}$. Blundell et al. (2000) show for the multivariate case that a sufficient (but not necessary) condition for $\mathrm{E}\left[\omega_{i, t} \mu_{i}\right]=0$ with $\omega_{i, t}$ being any covariate is that $\omega_{i, t}$ is mean-stationary.

The moment conditions in (46)-(49) read in compact matrix notation

$$
\mathrm{E}\left[\mathbf{Z}_{i}^{l e v^{\prime}} \mathbf{u}_{i}\right]=0
$$

where

$$
\mathbf{u}_{i}^{l e v}=\left(\varepsilon_{i, m+1}, \varepsilon_{i, m+2}, \ldots, \varepsilon_{i, T_{i}}\right)^{\prime}
$$

is a $\left(T_{i}-m\right)$ vector comprising the idiosyncratic error terms of the level equation and $\mathbf{Z}_{i}$ is a block diagonal matrix, $\mathbf{Z}_{i}^{\text {lev }}=\operatorname{diag}\left[\mathbf{Z}_{i}^{\text {lev },(m+1)}, \mathbf{Z}_{i}^{\text {lev },(m+2)}, \ldots, \mathbf{Z}_{i}^{\text {lev, }\left(T_{i}\right)}\right]$, with

$$
\mathbf{Z}_{i}^{l e v,(t)}= \begin{cases}\left(0, \boldsymbol{\Delta} \mathbf{x}_{i, t}^{\prime}, \Delta \mathbf{w}_{i, t}^{\prime}, \mathbf{0}^{\prime}\right) & \text { for } t=m+1 \\ \left(\Delta y_{i, t-1}, \Delta \mathbf{x}_{i, t}^{\prime}, \Delta \mathbf{w}_{i, t}^{\prime}, \Delta \mathbf{v}_{i, t-1}^{\prime}\right) & \text { for } t=m+2, \ldots, T_{i}\end{cases}
$$

The System GMM estimator can be obtained by combining the moment conditions of the difference equation and the moment conditions of the level equation, i.e.

$$
\mathrm{E}\left[\mathbf{Z}_{i}^{\text {sys' }} \mathbf{u}_{i}^{\text {sys }}\right]=0
$$

where

$$
\mathbf{u}_{i}^{\text {sys }}=\left(\Delta \mathbf{u}_{i}^{\prime}, \mathbf{u}_{i}^{\prime}\right)^{\prime}
$$

and

$$
\mathbf{Z}_{i}^{\text {sys }}=\left[\begin{array}{cc}
\mathbf{Z}_{i}^{\text {dif }} & 0 \\
0 & \mathbf{Z}_{i}^{\text {lev }}
\end{array}\right]
$$

is a stacked matrix of the difference and level instruments. After stacking the observation matrices $\mathbf{y}$ and $\mathbf{X}$ correspondingly, the one-step and two-step System GMM estimators can be derived as described in section $\mathrm{B}$.

\section{Robustness check of the estimation results}

To check the robustness of the results, we consider some variations of the model estimated above. In particular, we consider the following modifications: First, we vary the lag length and additionally consider models with $L=3$ and $L=5$. Second, we use gross values of the variables in the investment function rather then values net of depreciation. Third, we estimate the investment model for the manufacturing sector only.

Figure 7 plots the results of the recursive two-step System GMM estimation of (20) for $L=3,4,5$. Overall, the results derived from the baseline specification with $L=4$ are fairly 

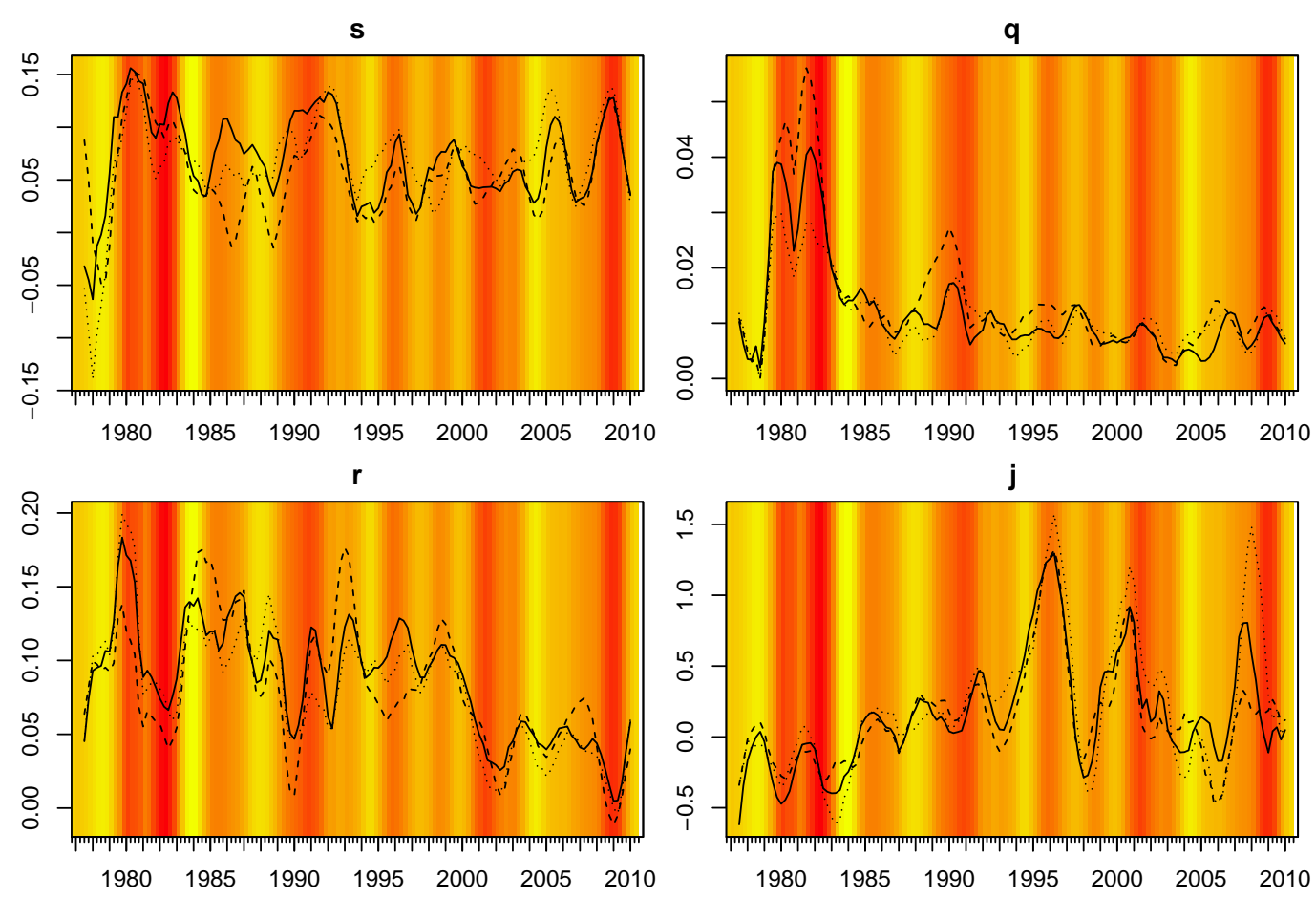

Figure 7: Regression results for the two-step System GMM estimation of (20) with $L=3$ (dashed line), $L=4$ (solid line) and $L=5$ (dotted line)

robust to the lag length chosen. Some notable deviations from the standard specification occur around 1986 for the sales-growth coefficient and in 1995 for the cash-flow coefficient.

To further check the robustness of our results we consider an investment function with variables gross of depreciation, i.e

$$
\begin{aligned}
g_{i, t}^{g} & =\sum_{k=1}^{L} \beta_{g, k} g_{i, t-k}^{g}+\sum_{k=0}^{L} \beta_{s, k} s_{i, t-k}^{g}+\sum_{k=0}^{L} \beta_{r, k} r_{i, t-k}^{g}+\sum_{k=0}^{L} \beta_{q, k} q_{i, t-k} \\
& +\sum_{k=0}^{L} \beta_{j, k} j_{i, t-k}+\sum_{s=0}^{4} \beta_{d, s} d_{s}+\mu_{i}+\varepsilon_{i, t}
\end{aligned}
$$

where $g_{i, t}^{g}$ is the gross accumulation rate, $s_{i, t}^{g}$ is the growth rate of gross sales and $r_{i, t}^{g}$ is the ratio between cash flow including depreciation and the net capital stock. Again, $L=4$.

The smoothened long-run coefficients estimated using two-step System GMM on a 5quarter rolling window are plotted in Figure 8 for the investment specification in net and in gross values. The coefficients for sales growth and Tobin's $q$ are fairly consistent with each other which is not surprising as the growth rates of net and gross sales are very similar and Tobin's $q$ is the same in both specifications. The cash-flow and cost-of-capital coefficients 

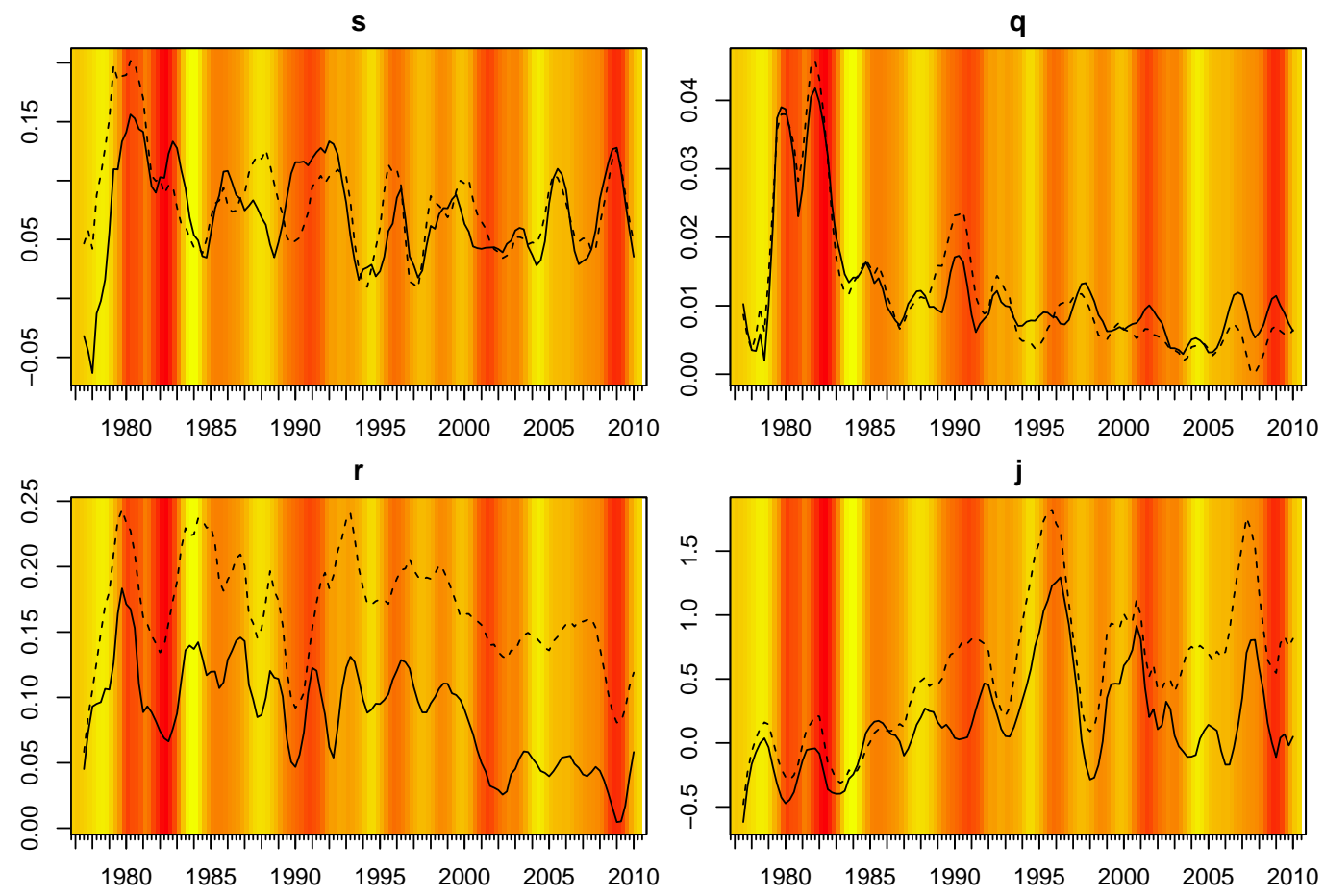

Figure 8: Regression results for the two-step System GMM estimation of (20) in net variables (solid line) and of (56) in gross variables (dashed line)

are, on average, higher than the ones in the baseline specification, but exhibit the same cyclical pattern.

Finally, the estimates for the total corporate business sector excluding financial, insurance and real estate services are compared to estimates for different sub-sectors, in particular for all industries including agriculture, forestry, fishing, mining, construction, manufacturing, transportation, communications, electric, gas, and sanitary services (SIC codes smaller than 5000) as well as the manufacturing sector alone (SIC codes between 3000 and 4000).

The estimation results are plotted in Figure 9. Note that total industries and manufacturing imply only $3 / 4$ and $1 / 2$, respectively, of the observations available for the total business sector. This may contribute to the higher volatility of the coefficients of the smaller sectors. The results for the total industries are very similar to the baseline results. Exceptions are the sales-growth coefficient which does not spike in the late 1990s, the cash-flow coefficient spiking in the late 1970s which might be a consequence of a lack of observations and in the mid 1980s as well as the coefficient of Tobin's $q$ deviating from the baseline result in the mid 1980s.

The coefficients obtained for the manufacturing sector alone exhibit more significant deviations. It is worth to note that the manufacturing sector seems to be affected by demand 

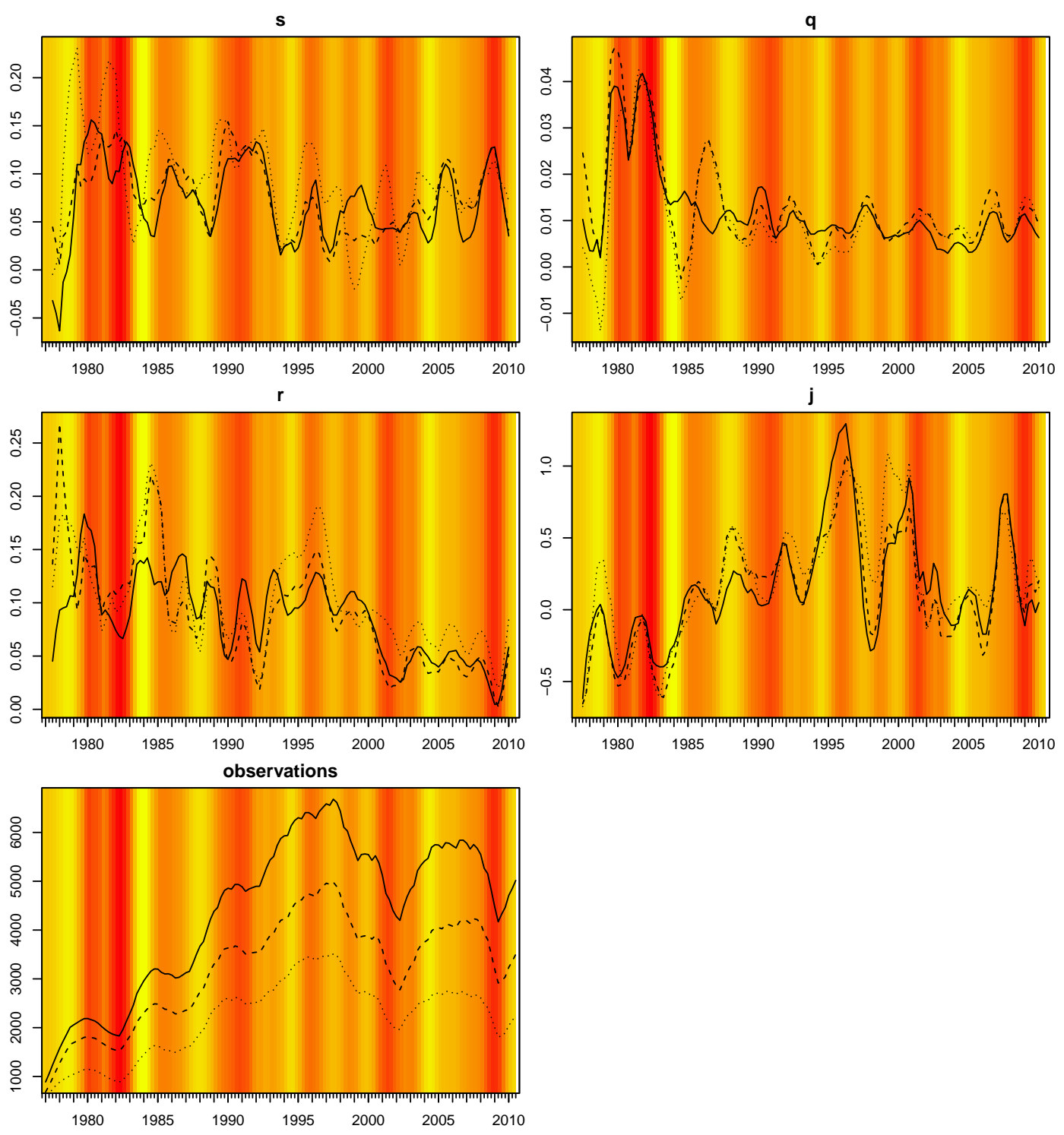

Figure 9: Regression results for the two-step System GMM estimation of (20) for the the total business sector (solid line), for the industries (dashed line), and for the manufacturing sector (dotted line)

constraints prior to the rest of the economy as the sales-growth coefficient seem to spike slightly before the average over the total business sector. Further, demand constraints seem to be more pronounced for the manufacturing sector. 
Publisher: Hans-Böckler-Stiftung, Hans-Böckler-Str. 39, 40476 Düsseldorf, Germany Phone: +49-211-7778-331, IMK@boeckler.de, http://www.imk-boeckler.de

IMK Working Paper is an online publication series available at: http://www.boeckler.de/imk 5016.htm

ISSN: $1861-2199$

The views expressed in this paper do not necessarily reflect those of the IMK or the Hans-Böckler-Foundation.

All rights reserved. Reproduction for educational and non-commercial purposes is permitted provided that the source is acknowledged. 